\title{
El siglo XVI en los lienzos de Coixtlahuaca
}

\section{Sebastian van Doesburg}

\section{OpenEdition \\ Journals}

\section{Edición electrónica}

URL: https://journals.openedition.org/jsa/1489

DOI: $10.4000 /$ jsa. 1489

ISSN: 1957-7842

Editor

Société des américanistes

\section{Edición impresa}

Fecha de publicación: 5 junio 2003

Paginación: 67-96

ISSN: 0037-9174

\section{Referencia electrónica}

Sebastian van Doesburg, «El siglo xvı en los lienzos de Coixtlahuaca», Journal de la Société des américanistes [En línea], 89-2 | 2003, Publicado el 05 junio 2008, consultado el 02 septiembre 2022. URL: http://journals.openedition.org/jsa/1489 ; DOl: https://doi.org/10.4000/jsa.1489 


\title{
EL SIGLO XVI EN LOS LIENZOS DE COIXTLAHUACA
}

\author{
Sebastian Van DOESBURG *
}

Los tres grandes lienzos provenientes del señorío de Coixtlahuaca (Parmenter 1970 ; König 1984) muestran, entre la información sobre la historia política de la época prehispánica, varias escenas representando acontecimientos de la época colonial temprana. Estas escenas se destacan por la presencia de administradores españoles. En este artículo propongo identificar a las personas representadas en estas escenas e intento reconstruir una razón por la inclusión de estas escenas en los documentos. [PALABRAS CLAVES : etnohistoria, lienzos, códices, Coixtlahuaca, Oaxaca, ngiwa.]

The Sixteenth Century in the Coixtlahuaca Lienzos. The three large lienzos painted in the city-state of Coixtlahuaca (Parmenter 1970 ; König 1984) show, among the information on the prehispanic political history, several scenes that represent events ocurring during the early colonial period. These scenes stand out for the appearance of Spanish administrators. In this article, I propose an identification for the people represented in these scenes and I attempt to reconstruct a reason for the inclusion of these scenes in the document. [KEY worDs : ethnohistory, lienzos, codices, Coixtlahuaca, Oaxaca, ngiwa.]

Le $x v t^{e}$ siècle dans les lienzos de Coixtlahuaca. Les trois grands lienzos peints dans la cité-État de Coixtlahuaca (Parmenter 1970 ; König 1984) montrent, à côté des informations concernant l'histoire politique précolombienne, plusieurs scènes représentant des événements qui se sont déroulés au début de la période coloniale. Ces scènes sont reconnaissables grâce à des représentations d'administrateurs espagnols. Dans cet article, je tente d'identifier les personnages représentés dans ces scènes et de déceler la raison de leur présence dans ces documents. [MOTS CLÉs : ethno-histoire, lienzos, codex, Coixtlahuaca, Oaxaca, ngiwa.]

\section{INTRODUCCIÓN}

Durante la llamada época posclásica tardía (1250-1520 d.C.), la ciudad de Coixtlahuaca se desarrolló hacia uno de los centros económicos principales del suroeste de México (véanse los mapas. Figuras 1 y 2). La ubicación de esta gran ciudad, de unos 15 mil habitantes, entre los llanos poblanos del centro de México y las serranías de la Mixteca, la convirtió en un puerto de comercio, en donde se reunieron y trocaron productos exóticos de regiones distantes. A mediados del siglo XV, este gran mercado fue controlado por el rey Atonaltzin, un descendiente

\footnotetext{
* CONACYT / Centro INAH Oaxaca, Pino Suárez 715, Oaxaca, Centro, 68000, Mexique [basborb@hotmail.com].
}

Journal de la Société des Américanistes, 2003, 89-2, pp. 67-96. OSociété des Américanistes. 


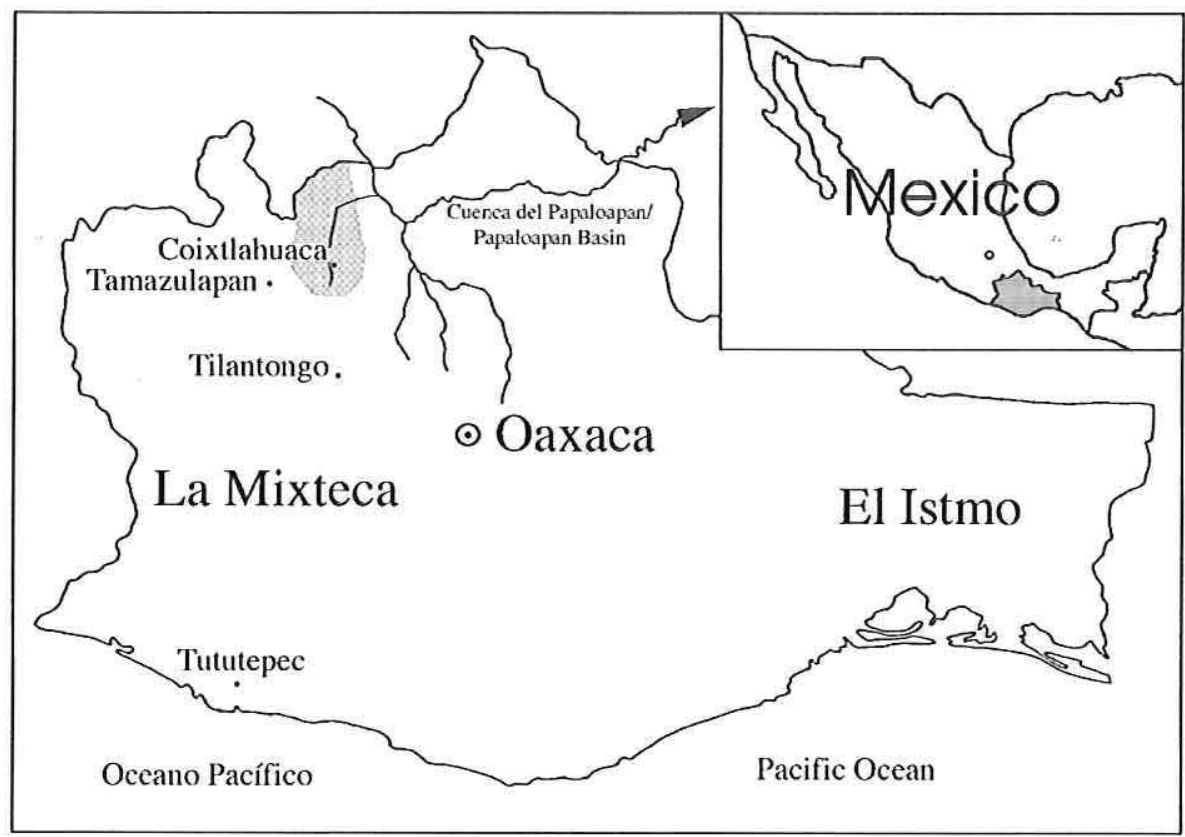

FIG. 1 - Ubicación del valle de Coixtlahuaca en el norte del Estado de Oaxaca.

de un prestigiado linaje de orígenes toltecas. Conscientes de la ubicación estratégica de Coixtlahuaca, los aztecas atacaron el reino en 1458 d.C. y, después de algunos años de asaltos, Motecuhzoma venció y mató a Atonaltzin, llevándose de regreso un buen número de cautivos para ser sacrificado en la capital azteca. Los aztecas dieron gran importancia a esta conquista y sus relatos históricos contienen extensas versiones de este evento (Duran 1984, tomo II, cap. XXII y XXIII ; Torquemada 1986, libro II, cap. XLVIII ; Anales de Cuauhtitlan 1975, pár. 189 y 238). Pocos años después, en 1520 , la región sufrió la invasión europea. Mientras el siglo Xvi aún puede considerarse, a pesar de los horrores de la colonización, un periodo de gran florecimiento cultural, la marginalización económica de la población indígena en los siglos posteriores marcó el destino de la región. Además, desde tiempos antiguos el árido valle sufrió y sufre de una severa erosión y desertificación, dando estos elementos como resultado en la actualidad un muy elevado índice de migración de la fuerza de trabajo hacia otros lados.

Anteriormente, el valle albergó distintos grupos étnicos : durante el siglo XVI había hablantes del tu'un savi o mixteco, del nahuatl y del ngiwa o chocho. Esta 


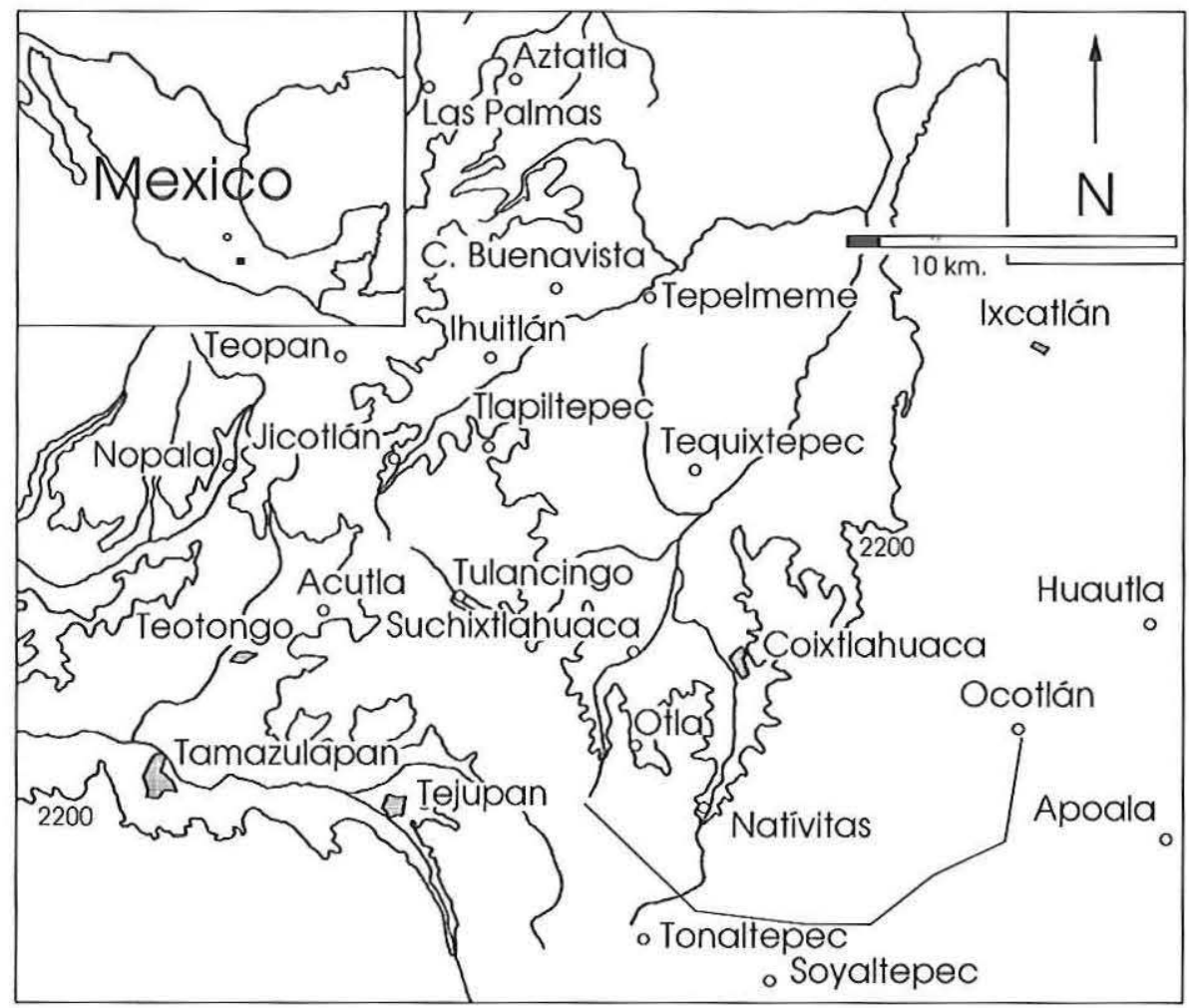

Fig. 2 - Extensión de la lengua ngiwa : el valle de Coixtlahuaca y la parte norte del valle de Tamazulapan.

última lengua, que aún persiste en algunos pueblos de la región, aunque en riesgo de desaparecer, es un pariente muy cercano de la lengua popoloca que se habla en el sur de Puebla. A partir de las últimas décadas del siglo Xvi, y trás el impulso dado por los domínicos del convento de Santa María Tamazulapan, el ngiwa tuvo gran éxito como lengua escrita, pero al iniciarse el siglo XIX, esta tradición llegó a su fin (Doesburg and Swanton en prensa).

Antes de la introducción de esta escritura alfabética en ngiwa, los señores de Coixtlahuaca registraron sus orígenes, linajes y hazañas en la hermosa escritura pictográfica en uso en grandes partes del centro y suroeste de México durante la época posclásica. Por su carácter pictográfico, esta escritura resolvió de manera elegante la situación del polilingüismo. Hoy existen aún doce documentos pintados en esta escritura, la mayoría elaborados en grandes telas de algodón a mediados del siglo XVI. Estas telas, llamadas "lienzos », contienen historias 
reales que a veces se remontan hasta el inicio de la época posclásica. Comunmente, son vistos como « pruebas » o « defensas » elaboradas por los indígenas para ser presentadas ante la administración colonial ${ }^{1}$. El contenido de este extraordinario grupo de documentos ha sido aclarado durante los últimos cincuenta años en varias publicaciones especializadas ${ }^{2}$.

Uno de los principales problemas en el estudio de los Lienzos de Coixtlahuaca es la ausencia de una clara correspondencia entre las personas mencionadas en los lienzos y los gobernantes indígenas mencionados en los documentos virreinales. En su breve comentario de los Lienzos de Coixtlahuaca, Alfonso Caso (1979, pp. 134-136) ya señaló la existencia de varias escenas representando personajes de la época colonial ; sin embargo, no llegó a identificar ninguno de estos en la documentación colonial. Como se ha demostrado en varios estudios de los códices mixtecos, el establecimiento de tales relaciones es fundamental en vislumbrar el lugar, las fechas y las razones de la elaboración de los documentos (por ejemplo Caso 1949 ; 1979, pp. 110-117 ; Jansen 1998; Jansen y Pérez J. 2000, pp. 24-26, pp. 86-100, pp. 176-178 ; König 1979) ${ }^{3}$. Mientras que este hecho ha resultado en un interés particular de los codicistas en la documentación colonial temprana de la Mixteca y, posteriormente, de otras regiones, la recopilación sistemática de datos coloniales del valle de Coixtlahuaca es de fechas muy recientes (Doesburg 2002). En este artículo se propone una posible conexión entre algunos personajes en los Lienzos de Coixtlahuaca y ciertos individuos mencionados en los documentos coloniales de Coixtlahuaca ${ }^{4}$.

\section{Los CACIQUES COLONIALES DE COIXTLAHUACA, SIGLO XVI}

Como primera parte de nuestro argumento, veremos ahora los datos disponibles acerca de los caciques de Coixtlahuaca durante el siglo xvi. Un importante documento al respecto, procedente de Tejupan, ofrece la principal pista para la reconstrucción genealógica de los tempranos caciques coloniales de Coixtlahuaca. El mencionado documento es una copia tardía (siglo XVIII) de un original fechado en 1572. El caso descrito en el manuscrito concierne una disputa sobre la sucesión en el cacicazgo de Tejupan entre tres importantes nobles : Gregorio de Lara, Felipe de Austria y Juan de Zúñiga. Dejando a un lado las interesantes declaraciones de los primeros dos, Juan de Zúñiga, alcalde y principal de Coixtlahuaca y natural de Tejupan, reclama el cacicazgo con el siguiente argumento :

[...] él era hijo legítimo y el mayor de don Domingo de Mendoza y de doña Ana su muger, que habían sido caciques de el [pueblo de Tejupan] y el dicho su padre había sido hijo mayor y heredero legítimo de Teilteutle y Acabeuchil su muger, caciques que habían sido, a los cuales él había sucedido legítimamente. (AGN, Tierras, vol. 34, exp. 1, f. 3) 
Poco después, Juan de Zúñiga se desiste del pleito y declara en favor de Gregorio de Lara. Como demuestran los muchos documentos posteriores relacionados con el cacicazgo de Gregorio de Lara en los distintos archivos, este último logró de hecho establecer un dominio fuerte y duradero en Tejupan ${ }^{5}$.

Ahora bien, mientras que el papel de Juan de Zúñiga en Tejupan quedó reducido al de un noble local, su posición en Coixtlahuaca siempre fue prominente. Ya en 1552, los nobles de Coixtlahuaca presentaron a los niños Juan y su hermano mayor Pedro ante el virrey ${ }^{6}$. La coincidencia en el nombre del padre sugiere que se trate probablemente del mismo don Juan de Zúñiga y un hermano suyo. El registro de esta visita a la Real Audiencia, confirma la ascendencia de don Juan :

Yo, don Luis de Velasco, visorrey etc. Por quanto por parte de don Pedro y don Juan, naturales y prençipales del pueblo de Cuestalauaca, me an fecho rrelaçion que ellos son hijos legitimos de don Domingo, señor que fue del d[ic]ho pueblo, y quedaron ninos de hedad de fasta seys años poco mas o menos, y que el d[ic]ho su padre tenia çierta tasaçion de lo que se les auia de dar, la qual ante mi presentaron [y] quera : cada un año una simentera de mayz de do(s)ientas y sesenta braças en largo y çiento y quarenta en ancho, cada quatro meses diez gallinas de la tierra, quatro mill cacaos, dos mill capullos de algodon que el mercaua para que se hilasen y hiziesen mantas y le rreparasen sus casas; el qual trebuto perteneçia a ellos como a hijos del d[ic]ho don Domingo, y me fue pedido mandase les acudiesen con ellos.

Y por mi visto lo susod[ic]ho y que los prençipales del d[ic]ho pueblo declar(ar)on ante mi que lo dauan a su padre, lo darian a sus hijos con tanto que en lugar de las gallinas, cacao y algodon rresçibiesen quinze pesos de oro a ocho rreales cada uno, cada çinquenta dias de sobras de trebutos, por la presente mando que de aqui adelante, fasta tanto que otra cosa se provea, de las sobras de trebutos que obiere en el d[ic]ho pueblo de Cuestalavaca se den al d[ic]ho don Pedro y don Juan, hijos del d[ic]ho don Domingo, quinze pesos de oro comun de a ocho rreales cada uno, cada çinquenta dias y les fagan cada un año las simenteras de mayz que les solian hazer al d[ic]ho su padre y les rreparen sus casas. Y por quanto los susod[ic]hos don Pedro y don Juan son menores mando que tengan cargo de sus bienes y personas y como su curador Esteuan de San Juan, prençipal del d[ic]ho pueblo y como tal curador tenga espeçial cuydado de mirar y procurar el bien dellos y de aumentar y acreçentar su hazienda para que vaya a rrecaudo que convenga y della tenga quenta y rrazon para la dar cada y quando le sea pedido. Fecho en Mexico, a primero dia del mes de otubre de mill y qui[nient]os y çinquenta y dos años. Don Luis de Velasco. Por mandado de su s[eñori]a, Antonio de Turçios. (Newberry Library, Chicago, Edward E. Ayer Collection, MS. 1121, f. 128, $128 \mathrm{vta})$

De este texto podemos deducir que don Pedro y don Juan nacieron alrededor del año de 1546 y que su padre, don Domingo de Mendoza, murió en 1552. Antes de seguir con la vida de don Pedro y don Juan, conviene recopilar los datos acerca de su padre, don Domingo de Mendoza. En un interesante y muy prolongado pleito sobre estancias entre Tequixtepec y Coixtlahuaca por un lado y 
Tamazulapa por otro lado, la partida de Coixtlahuaca se introduce en una carta de 1544 como :

Don Domingo, caçique e menor de hedad de Cuestlabaca, de beynte e çinco a[ñ]os, y el conçejo e justiçia de Cuestlavaca como pueblo q[ue] no tiene caçique ni prinçipales por estar todos echados a las minas por su mag[estad]. (AGN, Indios, vol. 101, exp. 1, f. 10vta)

Añade en su carta que : « el pueblo de Cuestlavaca esta syn prinçipales e señor que sabe la justiçia, la verdad questan en destierro cada vn prinçipal » (ibid., f. 11). Esta cita nos indica que don Domingo debió nacer alrededor del año de $1519^{7}$. En el año de su muerte, este cacique tenía entonces sólo 33 años de edad. Otra carta del mencionado pleito, fechada en 1540, nos enseña que don Domingo, igual que sus hijos, creció bajo la tutela de un coadjutor. En este escrito, se resume la queja de Coixtlahuaca en la siguiente manera :

Sepades q[ue] por parte de don Domingo, yndio caçique del pueblo de Cuestalavaca, e de los naturales $\mathrm{d}[\mathrm{e}] \mathrm{l}$, nos fue f $[\mathrm{ec}]$ ha rrelaçion por su petiçion, diziendo que al tiempo $\mathrm{q}[\mathrm{ue}]$ su padre fall[eci]o desta presente vida, el quedo de hedad de hasta quatro o çinco anos poco mas o menos, e que por no ser de hedad avia gouernado el d[ic]ho pueblo un don Fran[cis]co, ya dif[u]nto, e otro que se dize don Diego, questa en el d[ic]ho pueblo ; e theniendo la d[ic]ha gouernaçion por su propia auturidad, en su perjuiz[i]o e de los maçeguales e naturales $\mathrm{d}[\mathrm{e}] \mathrm{l} \mathrm{d}[\mathrm{ic}]$ ho pueblo, enajenaron çiertas estançias con sus maçeguales, tierras e labranças, e q[ue] heran d[e]l d[ic]ho pueblo e las avian thenido sus antepasados de tiempo ynmemorial a esta parte, dandolas a un don Fran[cis]co, caçique del pueblo de Tequeçistepeque. (AAT-55a, 1540)

De esta cita se deriva que el padre de don Domingo de Mendoza, aparentemente el ya mencionado Teilteutle, murió alrededor del año de 1523-1524. Por este y otros documentos parece que a partir de este momento, el gobierno de Coixtlahuaca quedó en manos de los hermanos don Francisco y don Diego (AGN, Jesuitas, vol. 1-14, exp. 107, s/f ; AAT-31, s/f). No sabemos con certeza cuál fue la relación familiar de don Domingo y los hermanos tutores, pero es posible que estos hayan sido tíos del menor. Como indica el texto del documento, don Francisco murió ya antes de 1540. Don Diego, sin embargo, lo encontramos de nuevo en el año de 1551, cuando es objeto de una investigación en su contra por derramas (cobranza de tributos indebidos). Los pocos y breves textos relacionados al juicio han sido publicados por Silvio Zavala en 1982. El 16 de mayo de 1551, la audiencia real dió comisión a Domingo Fernández, un principal de Talistacapa que actuaba como juez de comisión, para investigar la queja de los de Coixtlahuaca, sobre que su cacique [don Diego] les ha llevado tributos fuera de la tasación (Library of Congress, Washington D. C., Hans P. Kraus Collection, MS. 140, f. 131vta, 132 ; AGN, Mercedes, vol. 3, f. 368vta). En el segundo documento, del 22 de octubre de 1551 , 
el virrey Velasco hace saber a Francisco de Valdiuieso, corregidor en el pueblo de Tequaco, que don Diego, gobernador del pueblo de Cuesta[la]vaca, ha hecho relacion al virrey que Domingo Fernandez fue por juez al dicho pueblo, el cual le hizo ciertos cargos tomando por testigos a sus enemigos y contrarios, y que sin le oir ni recibir sus descargos mando que no fuese tenido por gobernador, ni le acudiesen con la comida y tributo que le esta señalado, diciendo que debe mucha cantidad de pesos de oro ; y pidio al virrey que, porque el no habia sido oido ni se habian averiguado los cargos que le hizo, nombrase una persona de confianza que fuese a averiguar lo suso dicho y que en el entretanto, porque el estaba libre de todo ello, no se le quitase el dicho cargo y se le acudiese con el dicho tributo y comida. Y por el virrey visto, confiando del dicho corregidor que bien y fielmente hara lo que le fuere cometido, y que el dicho Domingo Hernandez, que al presente esta por juez en el dicho pueblo, por la presente le manda que, luego que este mandamiento le fuere mostrado, vaya al dicho pueblo de Cuestalavaca y juntamente con el dicho Domingo Fernandez averigue todos los cargos que fueron hechos a don Diego, y reciba los descargos que tuviere; y sabido y averiguado la verdad de toda la culpa que contra el resultare, la averiguacion e informacion que sobre ello hiciere, firmada de su nombre y del dicho Domingo Fernandez, la envie ante el virrey para que vista se provea lo que convenga y sea justicia ; y en el entretanto mandara que tan solamente se le acuda a don Diego con la comida ordinaria que le pertenece y se le solia dar y no con otra cosa alguna. Y manda el virrey que en lo susodicho se ocupe ocho dias y lleve de salario cada un dia de los que en ello se ocupare un peso de oro comun a costa de culpados saliendo fuera de su jurisdiccion para lo cual que dicho es y para poder traer vara de justicia entendiendo en lo suso dicho le da poder cumplido. (Library of Congress, Washington D. C., Hans P. Kraus Collection, MS. 140, f. 252, 252vta)

Hay indicaciones que don Diego siguió vivo hasta por lo menos 1562 y que llevó el apellido de Castilla. Veremos algunas de las referencias a este cacique. En un documento de 1574, uno de los testigos relata como fue con don Diego a ver las tierras de Juquila en 1544 :

abra treinta a[ñ]os que fue este t[estig]o al pu[ebl]o de Questlauaca a uer al caçique don Diego, que a la sazon era uiuo, con el qual fue este t[estig]o a Xoquila y alli le enseño las salinas y agua salada y hasta donde llegauan sus ter[mi]nos, diziendole q[ue] todo era de Questlauaca. (AGI, Escribanía 160B, f. 1147vta)

Otra referencia muy temprana a don Diego de Castilla aparece en un texto en nahuatl de 1551 conservado en el Archivo Judicial de Oaxaca (AJT, Civil, leg. 21, exp. 10). En este texto, Diego de Castilla declara, ante el gobernador y alcaldes y ante el ya mencionado juez Domingo Hernández, que hace donación de un terreno en Aztatla a un tal Pedro Molina ${ }^{8}$. Regresando al documento del AGI, otro testigo narra de un viaje similar al ya mencionado, realizado aparentemente en 1559 con el cacique don Diego de Castilla :

dixo que la saue como en la preg[un]ta dize de oydas de mas de çinquenta a[ñ]os aca, y que lo uido por uista de ojos ser y pasar como la preg[un]ta dize de quinze a[ñ]os a esta 
p[ar]te, porque este t[estig]o fue a las salinas y est[anci]a de Xoquila con el caçique de Questlauaca, porq[ue] demas de auello uisto se lo dixo el d[ic]ho caçique llamado don Di[eg]o de Cast[ill]a. (AGI, Escribanía 160B, f. 1142)

De hecho, en el mismo año de 1559, don Diego de Castilla ocupa una posición importante en el recién instalado cabildo de Coixtlahuaca : en un documento conservado en el Archivo Antiguo de San Miguel Tequixtepec encontramos una enumeración de los miembros del cabildo :

a don Fran[cis]co, governador, y a don Diego de Cast[ill]a y a don Domingo de Mendoça, al[ca]ldes, y a don Thomas Vanegas y a don P[edr]o, prinçipales del pu[ebl]o de Cuextlavaca. (AAT-30, f. 10vta et passim) ${ }^{9}$

Este mismo cabildo, lo encontramos todavía en una merced de 1562 para el cacique Tomás de Vera de Santa María Nativitas, la cual se conserva en el Archivo municipal de este pueblo. Concluimos que durante la década de los 40, don Diego y don Domingo comparten el poder en Coixtlahuaca ; en 1552 don Domingo fallece, pero don Diego sigue vivo hasta por lo menos 1562 .

Regresando a los jóvenes don Pedro y don Juan, es interesante observar que no son sólo ellos que están en el poder, sino que lo comparten con dos tíos, llamados don Francisco y don Tomás ${ }^{10}$. Como vimos líneas arriba, en 1559 aparece la primera mención del cabildo encabezado por don Francisco (de apellido Maldonado), y en el que don Tomás Vanegas y don Pedro fungen como principales. Este grupo sigue en el poder hasta en los años 70 : al inicio de este parráfo vimos que Juan de Zúñiga era alcalde y principal en 1572. En el mismo año, su tío Tomás de Vanegas aparece como gobernador (AGI, Escribanía, 160B, pieza 4, f. 876) y un año antes, aparece un cabildo que consiste de don Francisco Maldonado, gobernador, don Tomás de Vanegas y don Juan de Zúñiga, alcaldes, y don Pedro de Mendoza, principal (AGI, Escribanía, 160B, pieza 4, f. 668, 774, 776vta, 826, 833, et passim). En 1573, don Pedro de Mendoza figura como cacique y principal con Tomás de Vanegas y Juan de Zúñiga como alcaldes (AGI, Escribanía, 160B, pieza 4, f. 1103vta, 1113vta y 1236). En 1579 se menciona a don Francisco de Maldonado como gobernador (AJT, Civil, leg. 21, exp. 10). Uno de los testigos del caso conservado en el AGI, Mateo de Santiago, declara que :

por ser como es prençipal e natural de la d[ic]ha est[anci]a de Xoquila sabe(l e bel) que en la d[ic]ha estançia e tierras della tienen tierras de arboles frutiferos e narangales e platanales los prençipales de Cuextlauaca del tiempo queste t[estig]o se sabe acordar e sus p[adr]es se lo dixeron a este t[estig]o, como son don P[edr]o de Mendoça e don Ju[an] de Çuñiga e don Tomas de Vanegas e don Fran[cis]co Maldonado, señores e prençipales en el pu[ebl]o de Cuextlauaca. (AGI, Escribanía, 160B, pieza 4, f. 1124vta, además f. 1128)

Después de 1574, ninguno de los dos hermanos, ni sus tíos siguen en el cabildo (AGI, Escribanía, 160B, pieza 4, f. 1282), y parece que les relevan otros caciques. 
Sin embargo, en este mismo año ellos y el cabildo recibieron una tasación del virrey Martín Enrique, posiblemente para garantizar sus ingresos :

Tasaçion a los de Cuestlauaca. En la çiudad de Mex[i]co a doze dias del mes de h[enero] de mill e qui[nient]os y setenta e quatro años el $\mathrm{m}[\mathrm{uy}]$ ex[celen]te señor don M[art]in Enrriquez visorrey y gou[ernad]or e ca[pitan] general por su mag[estad] en esta Nueua España [etc.], aviendo (visto) lo pedido por el caçique del pu[ebl]o de Cuextlavaca (don P[edr]o), don Juan su her[ma]no, (e) don Tomas y don Fran[cis]co sus tio(s, el) gou[ernad]or e alcaldes y otros [o]ft[içia]les de la rrepu[bli]ca del d[ic]ho pu[ebl]o sobre que se les acresçiente el sal[ari]o que por tasaçion por mi dada les esta señalada su ex[elenci]a dixo q[ue] mmandava e mm[an]do q[ue] de las sobras de tributos e vienes de la d[ic]ha comunidad del d[ic]ho pu[ebl]o de Cuextlavaca se de en cada un año a cada uno de los suso d[ic]hos lo siguiente : -Primeramente a don P[edr]o caçique del d[ic]ho pu[ebl]o çiento e çinquenta pesos de oro comun : cl p[es]os. -Yten a don Ju[an] her[ma]no del d[ic]ho caçique sesenta p[es]os del d[ic]ho oro : lx p[es]os. -Yten a don Tomas y don Fran[cis]co sus tios a cada uno çinquenta p[es]os del d[ic]ho oro: c p[es]os. -Yten al gou[ernad]or ques o fuere del d[ic]ho pu[ebl]o ochenta pesos: lxxx p[es]os. -Yten a dos al[ca]ldes a cada uno doze pesos : xxiiii p[es]os. -Yten a diez rregidores a cada uno quatro pesos : $x l \mathrm{p}[\mathrm{es}] \mathrm{os}$. -Yten a un alguazil mayor seis $\mathrm{p}[\mathrm{es}] \mathrm{os}$ : vi p[es]os. -Yten a dos mayordomos a cada uno diez pesos : $\mathrm{xx}$ p[es]os. -Yten a dos escrivanos a cada uno ocho $\mathrm{p}[\mathrm{es}] \mathrm{os}$, con que no lleven $\mathrm{d}[\mathrm{e}] \mathrm{r}[\mathrm{ech}] \mathrm{os}$ de los negoçios : xvi p[es]os. -Yten a un rrelojero quatro pesos : iiii p[es]os. E no an de llebar ni lleuar otro sal[ari]o ni servi[ci]o de los maçeguales por rrazon de los d[ic]hos cargos ni en otra manera so pena de lo boluer el quatro tanto y de destierro del d[ic]ho pu[ebl]o por $\mathrm{t}$ [iem]po de quatro años $\mathrm{p}(\mathrm{re})$ çisos e questa tasaçion se guarde y cumpla entre tanto $\mathrm{q}[$ ue]otra cosa se [pro]vea y $\mathrm{m}$ [an]de e asi lo proveo e m[an]do. Don M[art]in Enrriquez. Por m[anda]do de su ex[elenci]a, Ju[an] de Cue[va]. (AGN, Indios, vol. 1, exp. 2, 1574)

Don Pedro de Mendoza aparece en un documento de 1576 acerca de un pleito sobre tierras en Tonala, llamadas Guechi (AGN, Tierras, vol. 232, exp. 1, ff. 1314). La parte contraria en el pleito es Francisco de Mendoza, el principal de Tepenene, cuyo linaje toma el poder después de 1574. Finalmente, don Juan de Zúñiga es mencionado todavía en 1588 (AGN, Mercedes, vol. 14, f. 150vta y 188) y en 1593 (AGN, Indios, vol. 6, II, exp. 811) en relación a unas estancias de ganado.

\section{ACONTECimientos COLONIALES EN LOS LIENZOS DE COIXTLAHUACA}

En esta segunda parte describiremos algunas de las imágenes que aparecen en los lienzos y que se refieren a acontecimientos de la colonia temprana. La primera imagen concierne a la impactante escena del ahorcamiento de un señor indígena enfrente de la iglesia de Coixtlahuaca representado en el Lienzo de Coixtlahuaca II (Figura 3). La muerte ocurre bajo los auspicios de un español sentado 


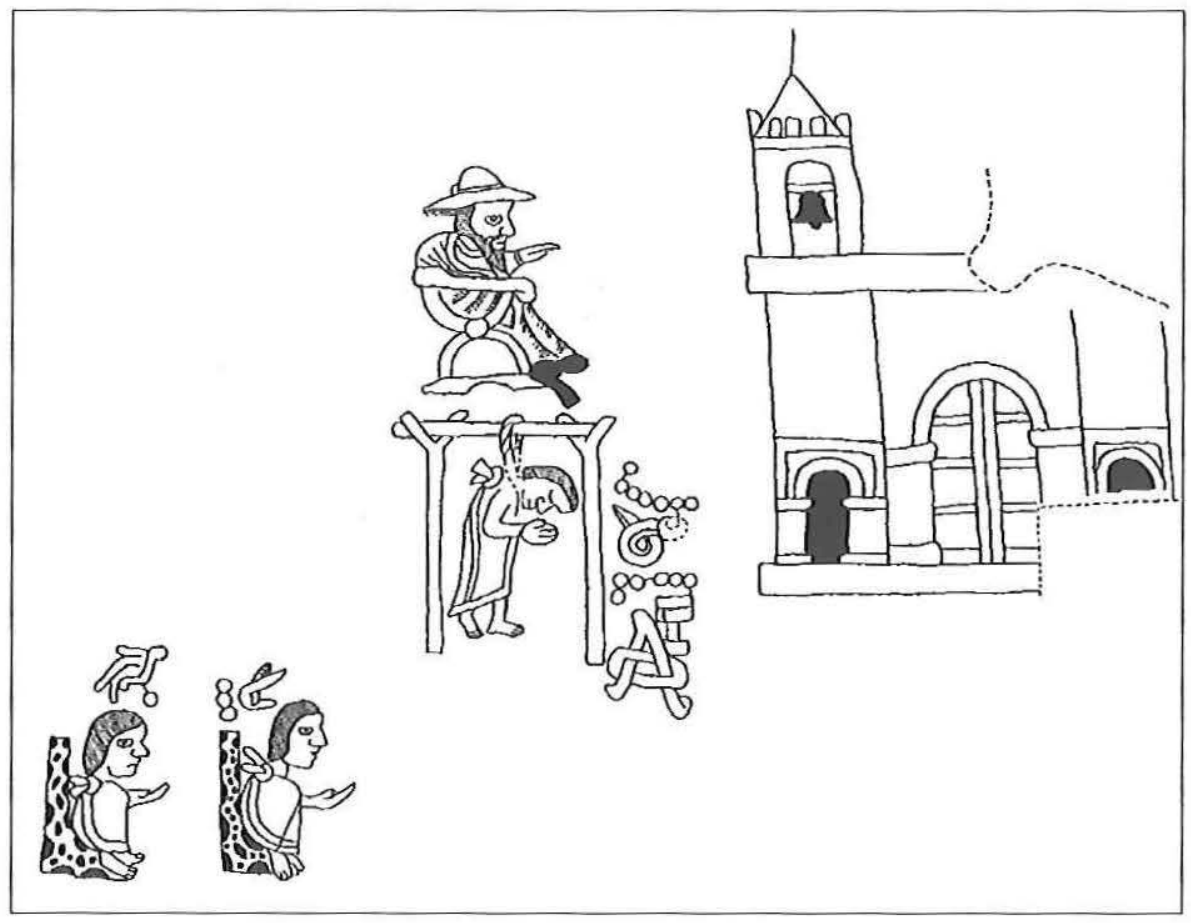

FIG. 3 - El ahorcamiento del señor de Coixtlahuaca en frente de la iglesia (Lienzo de Coixtlahuaca II). [Dibujo Bas van Doesburg]

en una silla de tijera. Verdugo y víctima son ambos anónimos. La fecha que acompaña a la imagen es Año Seis-Casa, día Siete-Serpiente. Según Alfonso Caso (1979, p. 134), esta fecha « sólo puede corresponder a 1577 ». Es incomprensible porqué Caso descartó la posibilidad de que la fecha correspondiera al año de 1525 , posibilidad que nos parece mucho más probable por varias razones :

1) El Lienzo de Coixtlahuaca II fue pintado anterior al año de 1556. Esta afirmación se basa en la presencia de fray Antonio de la Serna, vicario, y fray Domingo de Salazar en el Lienzo (Figuras 4a y 4b). Por el estilo muy diferente del dibujo de sus figuras en comparación con lo demás del lienzo, no existe duda que sus retratos fueron añadidos posteriormente al lienzo y es probable que la fecha de su inclusión sea 1556 : es en este año que fray Antonio de la Serna es vicario de Coixtlahuaca y fray Domingo de Salazar uno de sus conventuales (Vences Vidal 2000, p. 208).

2) Es más que probable que el ahorcamiento del señor indígena tuvo lugar en la anárquica época de la conquista y no en la segunda mitad del siglo XVI, cuando 


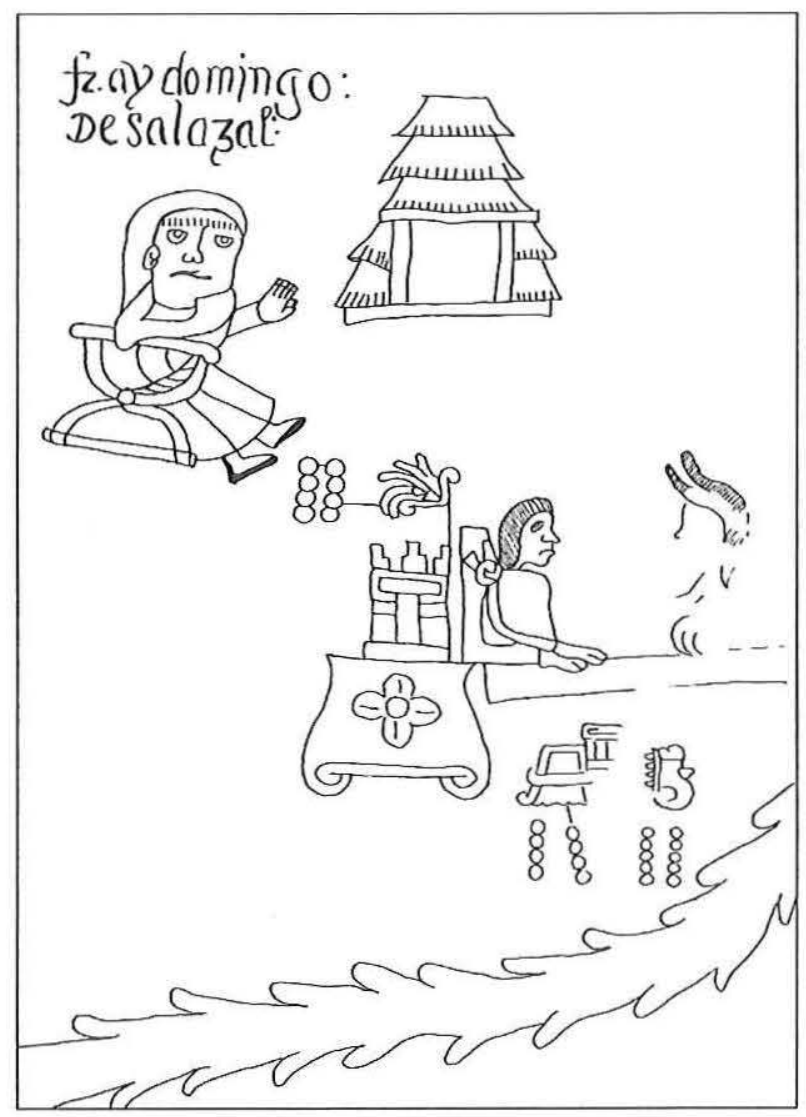

FIG. 4a - Fray Domingo de Salazar

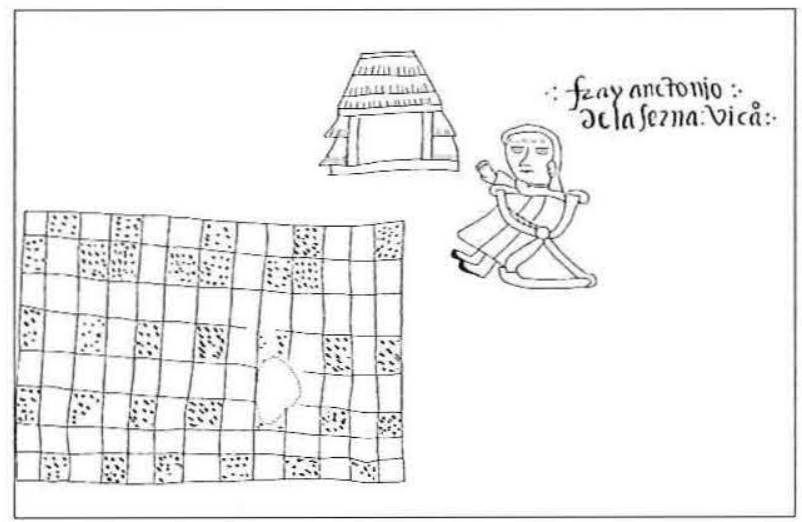

Fig. 4b - Fray Antonio de la Serna del convento de Coixtlahuaca (Lienzo de Coixtlahuaca II). La tabla de ajedrez en frente de Antonio de la Serna parece representar unas tierras que cultivaron los de Coixtlahuaca [Dibujo Bas van Doesburg] 
la administración española estaba bien instalada y, con algunas excepciones documentadas, ya no necesitaba de maneras tan drásticas para controlar a la población indígena.

Por lo mismo, es improbable que el español sea un obispo, como sugerió Caso (1979, p. 134). La fecha de 1525 es muy temprana para un juicio inquisitorial por " idolatría » en Oaxaca y la sentencia capital de la Inquisición consistía en la quema en la hoguera y no en el ahorcamiento (Greenleaf 1988, pp. 35-36) ${ }^{11}$. Pensamos que se trata más bien de un encomendero temprano o de uno de los capitanes de Cortés, ejecutando un juicio por « rebeldía ». En cuanto a la persona muerta, es posible que se trate de un cacique principal de Coixtlahuaca : en un documento tratando del heróico linaje de los señores de Coixtlahuaca, no había porqué incluir un ahorcamiento si éste no hubiera estado relacionado directamente con el linaje. Ahora bien, la fecha de 1525 coincide aproximadamente con la fecha de la muerte de Teilteutle, la cual hemos reconstruido para alrededor de 1523-1524. Por lo tanto, se propone aquí que el ahorcado sea el padre de Domingo de Mendoza. Desafortunadamente, no existe ninguna indicación explícita de que Teilteutle estuviese involucrado en una "rebeldía », aunque hay algunas referencias circunstanciales. La noticia de su hijo de que los principales de Coixtlahuaca fueron enviados a las minas, puede ser interpretada como parte de un castigo por "rebeldía ». Colgar al cacique y vender a los principales como esclavos para las minas era una práctica conocida en los primeros años de la colonia. La siguiente cita, que ilustra esta práctica, proviene de la Cuarta Carta (escrita en 1524) de Hernán Cortés y trata de una rebelión ocurrida en 1523 :

Y una de estas dos provincias, que se dice Tututepeque [cerca de Pánuco], se tornó a rebelar, y bajó de su tierra el señor con mucha gente, y quemó más de veinte pueblos de los de nuestros amigos, y mató y prendió mucha gente de ellos; y por esto, viniéndome yo de camino de aquella provincia de Pánuco, los torné a conquistar. Y aunque a la entrada mataron alguna gente de nuestros amigos que quedaba rezagada, y por las sierras reventaron diez o doce caballos, por el aspereza de ellas, se conquistó toda la provincia, y fué preso el señor y un hermano suyo, muchacho, y otro capitán general suyo que tenía la una frontera de la tierra ; y el cual dicho señor y su capitán fueron luego ahorcados, y todos los que se prendieron en la guerra hechos esclavos, que serían hasta doscientas personas ; los cuales se herraron y vendieron en almonedas [...]. La demás gente que en la dicha provincia quedó, vino de paz y lo está, y por señor de ella aquel muchacho, hermano del señor que murió. (Cortés 1963, pp. 206, 207)

De esta cita se desprende además que Cortés tuvo piedad del menor, el cual puso en el gobierno de la región para asegurar la continuidad del linaje indígena. En el caso de Coixtlahuaca, el niño don Domingo habría tenido el mismo papel. Por alguna razón, la rebelión de Coixtlahuaca nunca fue registrada, quizás porque ocurrió cuando Cortés andaba en su viaje por Yucatán y Guatemala. 
Como observó Caso en su comentario, el ahorcamiento es presenciado por dos señores indígenas sentados en asientos de piel de jaguar, llamados Señor Uno-Agua y Señor Tres-Viento ${ }^{12}$. Aquí propongo que estos señores sean idénticos a don Francisco y don Diego, los tutores de Domingo de Mendoza. Aunque esta identificación es asimismo de carácter especulativo, existen algunas indicaciones circunstanciales que la apoyan. En primer lugar tenemos el argumento de la fecha de la manufactura del lienzo, en los años anteriores a 1556, o sea aún en el gobierno de don Diego (y don Domingo, el cual no aparece).

Para el segundo argumento, tenemos que tornar a la segunda imagen de la época colonial que analizaremos en este artículo. Esta imagen trata de la visita de unos jueces españoles a Coixtlahuaca, representada en el Lienzo de Coixtlahuaca y el Lienzo A (Figura 5). Como ya observó Caso (1979, p. 135), los lienzos representan cuatro visitas. Los jueces españoles, anónimos, están montados en sus caballos y portan varas de justicia. Se distinguen además por sus barbas y sus sombreros espanõles. Cada visita está marcada por una fecha :

1) Año Ocho-Caña (1527) o Nueve Caña (1567), Día Doce-Pedernal.

2) Año Diez-Conejo (1542), Día Tres (i ?)-Casa.

3) Año Doce-Pedernal (1544), Día Dos-Perro.

4) Año Siete-Pedernal (1552), Día Cinco-(Jaguar ?).

Como observó Caso, la composición de la escena en esta parte de los lienzos parece guardar un orden cronológico, y su lectura debe efectuarse de la derecha a la izquierda ${ }^{13}$. Es por esto que coincidimos con Caso que la primera fecha debe leerse como Año Ocho-Caña. Ahora, los cuatro jueces españoles fueron recibidos por los mismos señores, testigos del ahorcamiento del cacique en el Lienzo de Coixtlahuaca II. En la primera visita, el juez fue recibido por el Señor Uno-Agua, en las tres restantes por el Señor Tres-Viento (curiosamente, el Lienzo A lo llama Uno-Viento). Ahora bien, en el párrafo anterior vimos que don Francisco, el mayor de los hermanos tutores, murió antes de 1540, mientras don Diego siguió vivo en 1551. Visto las fechas de las visitas, parece posible identificar don Francisco con el Señor Uno-Agua, y don Diego con el Señor Tres-Viento.

En el Lienzo A, dos de las visitas (la primera y la tercera) están conectadas a los linderos con Huautla a través de una línea, indicando que las visitas posiblemente estaban relacionadas con un problema de límites entre Coixtlahuaca y Huautla. En esta luz es intrigante la existencia de un breve mandamiento de 1552 dirigido a Gaspar de San Martín, corregidor de Cuicatlán. Como habrá observado el lector; la fecha del mandamiento coincide con la última visita de un juez español ${ }^{14}$.

Yo don Luis de Velasco, visorrey etc, fago saber a vos, Gaspar de San M[art]in, corregidor en el pueblo de Quicatlan y justiçia en çiertos pueblos comarcanos, que yo he sido ynformado que entre los yndios de Guabila [sic pro : Guautla] y Ustlauaca [sic 


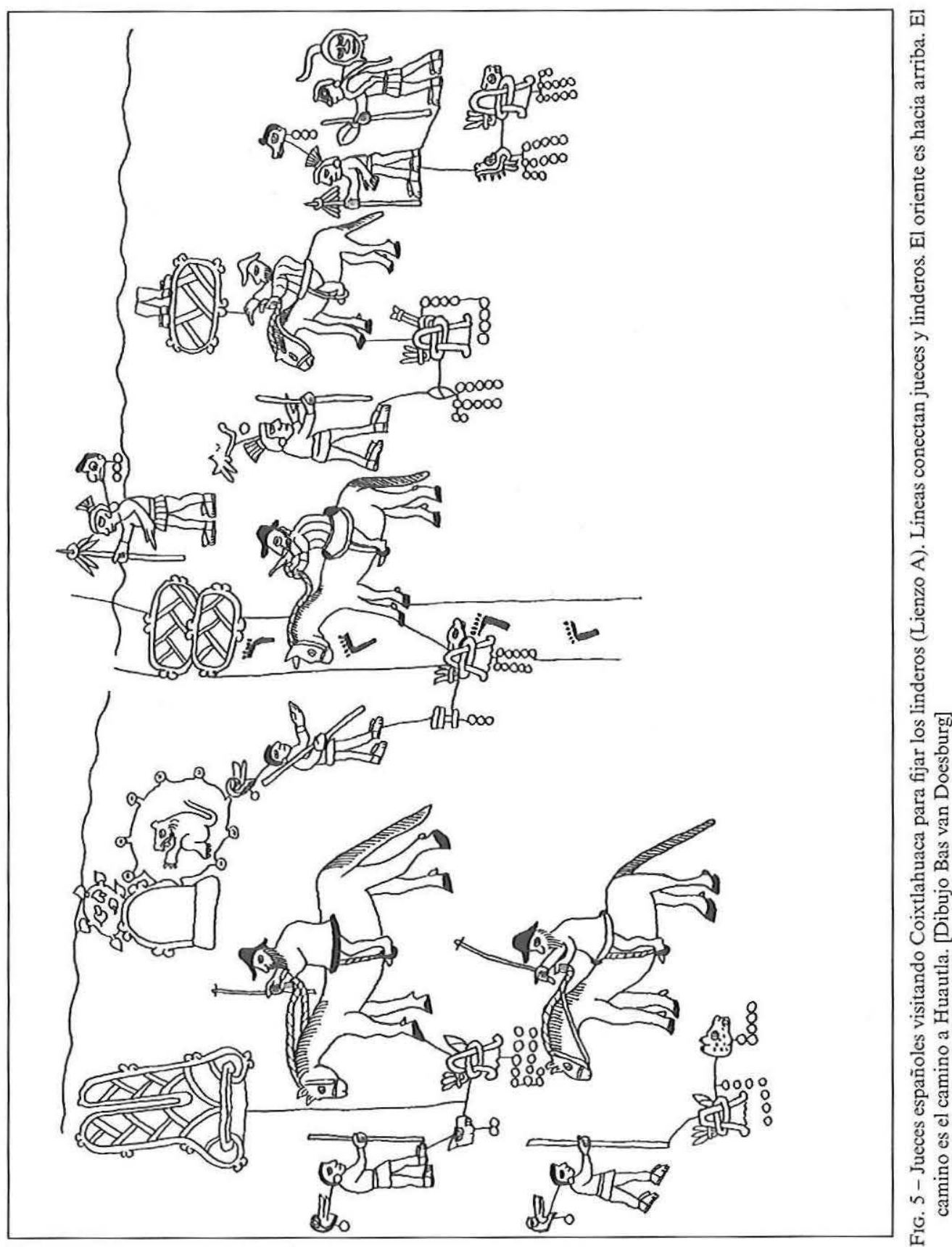


pro: Cuestlauaca] a auido y ay çiertas diferençias sobre los terminos y mojones de los $\mathrm{d}$ [ic]hos pueblos y tierras y otras cosas, y para que çesen entre hellos pleytos, costas y daños y otros ynconvinientes que de no se poder rremediar podrian subçeder, y para que entre ellos se escuse lo susod[ic]ho, me fue pedido lo cometiese a una persona de confiança para que entienda en lo susod[ic]ho y los pusiese en toda pas y conformidad [...]. (Newberry Library, Ayer Collection, MS. 1121, f. 185v. 186)

Visto lo anterior, y tomando en cuenta la selección de información presentada en el Lienzo de Coixtlahuaca y el Lienzo A, es probable que estos documentos fueron hechos durante el proceso de la creación de los límites coloniales de Coixtlahuaca. Así, los documentos registran las dos etapas en el origen de este lindero colonial : (1) la justificación de la extensión territorial del señorío prehispánico, representada a través de una serie de pequeñas conquistas sobre la línea fronteriza en distintas partes del lienzo, y (2) la afirmación de esta situación en forma de las mojoneras coloniales por la autoridad española.

Habiendo identificado a los principales actores políticos en Coixtlahuaca antes de 1552, nos resta la pregunta de la ausencia de don Domingo en los lienzos y la identidad del ahorcado. Por ahora, la ausencia de don Domingo sólo se explica por razones especulativas, como por ejemplo por el papel secundario que tuvo en relación a su tutor Diego, el cual, como veremos después, puede haber sido la persona que mandó pintar los lienzos. Puede ser que el regente trató de y (quizás con el apoyo de los encomenderos) logró oprimir al legítimo sucesor del señorío. En cuanto al segundo punto, como dijimos líneas atrás, puede tratarse del señor Teilteutle, pero aun así sigue en pie el problema de la ausencia de una clara conexión de la familia colonial que reconstruimos más arriba con los largos linajes dibujados en los lienzos. Veremos este problema en detalle. Son dos los lienzos que representan a los gobernantes de Coixtlahuaca cerca del momento de la conquista : el Lienzo de Ihuitlán expone, después del famoso rey Atonaltzin, del cual sabemos que murió entre 1458 y 1462 (Doesburg y Buren 1997, pp. 108109, 142), las siguientes cuatro parejas (Figura 6 parte de arriba hacia la izquierda enmarcada) :

Señor Once-Aguila y Señora Tres-Pedernal

Señor Once-Zopilote y Señora Tres-Serpiente

Señor Cuatro-Movimiento y Señora Siete-Lagartija

Señor Diez-Conejo y Señora Cinco-Venado

El Lienzo de Coixtlahuaca II presenta otra serie, a saber (Figura 7) :

Señor Cinco-Zopilote y Señora Cinco-Muerte

Señor Once-Zopilote y Señora Tres-Serpiente

Señor Tres-Perro y Señora Tres-Movimiento

Señor Diez-Conejo y Señora Cinco-Venado 


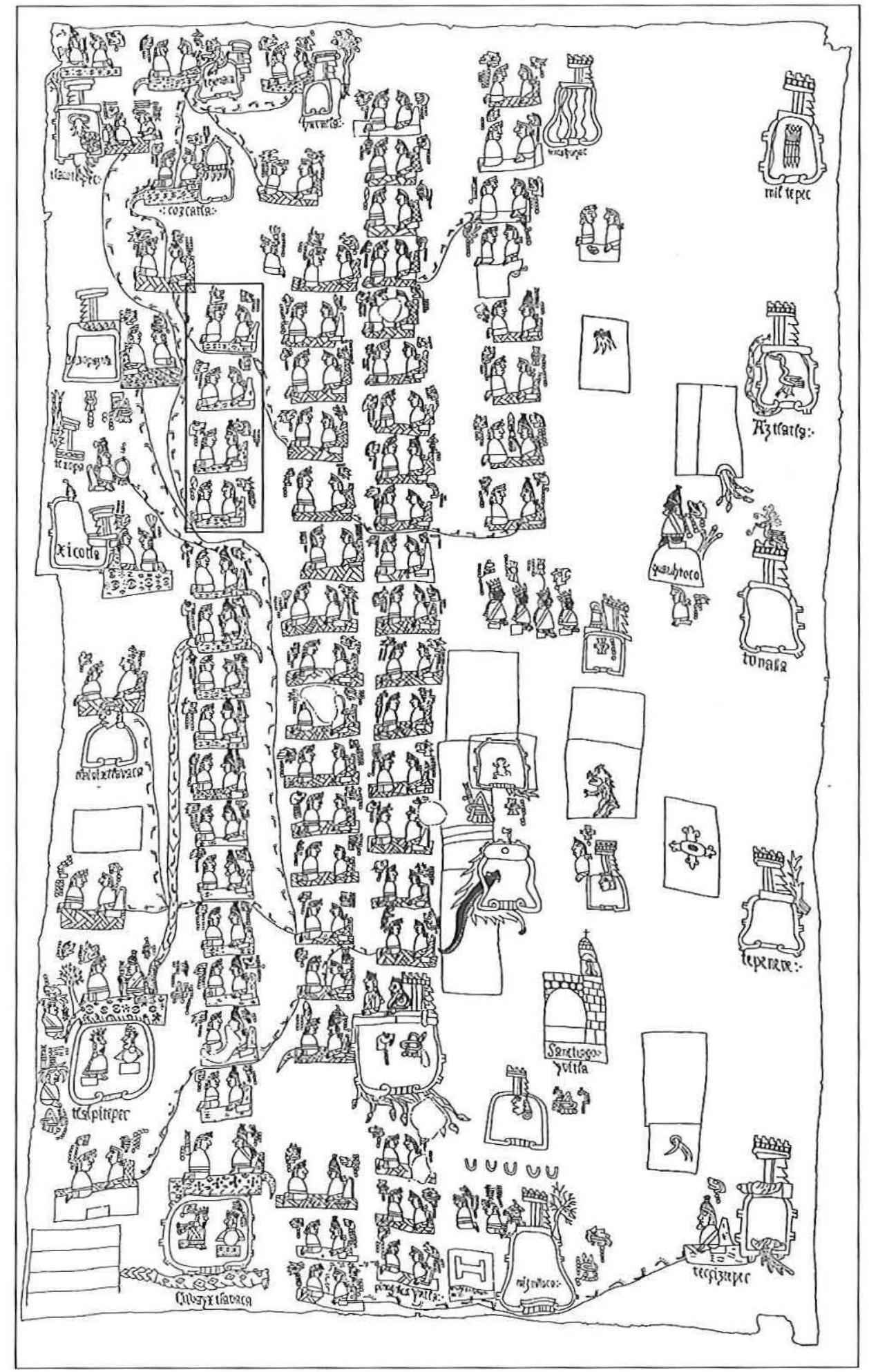

FIG. 6 - Las últimas cuatro generaciones de Coixtlahuaca (Lienzo de Ihuitlán). [Dibujo Martijn van de Bel, digitalizado por Bas van Doesburg] 


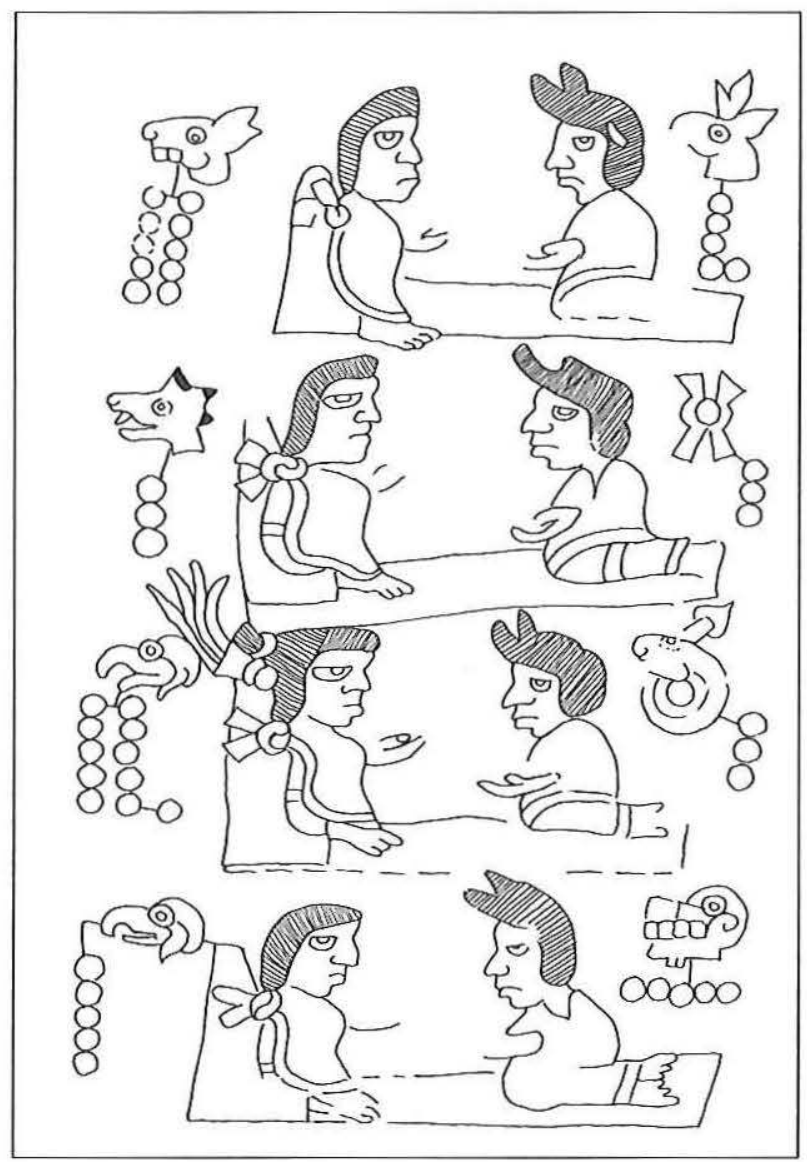

Fig. 7 - Las últimas cuatro generaciones de Coixtlahuaca (Lienzo de Coixtlahuaca II). [Dibujo Bas van Doesburg]

Las diferencias entre los dos documentos pueden reflejar un conflicto dinástico entre Ihuitlán y Coixtlahuaca ${ }^{15}$. Ahora, en cuanto al cuadro cronológico, cualquiera de las últimas tres generaciones puede haber estado gobernando al momento de la llegada de los españoles en 1520, lo que plantea un problema para establecer la relación entre la persona anónima ahorcada y el linaje debajo de sus pies ${ }^{16}$. Sin embargo, sea lo que sea la relación, nos encontramos con el problema de los nombres Teilteutle y Acabeuchil. Está claro que la ortografía de estos nombres en lengua nahuatl es bastante deficiente, y apenas se reconocen los elementos -teuctli (« señor ») y -suchil (« flor », indicador de nombres calendári- 
cos de mujeres). Lo demás es incierto ; por ejemplo, tomando en cuenta las posibles ambigüedades en la ortografía del siglo XVI, el nombre de la señora podría haber sido Ocelosuchil ("Señora con el nombre calendárico Ocelotl »), el cual no coincide con ninguno de los nombres calendáricos de las esposas de las últimas tres generaciones.

Hasta ahora, no hay manera de conectar estos nombres mal escritos de manera satisfactoria con los nombres de los últimos gobernantes en los lienzos.

Queda, como punto final, por especular acerca de la posible causa de la « rebelión ». No es difícil imaginarse las razones para una eventual sublevación en 1524. Ya antes, en la primera década del siglo xvi, Coixtlahuaca se había juntado a una sublevación general, planeada por el señor de Sosola, para liberarse del yugo azteca que desde 1458-1462 pesaba sobre Coixtlahuaca (Torquemada 1986, I, pp. 207-209). Es probable que la visita del cacique de Coixtlahuaca a Cortés en Izúcar en 1520 se debe a un mismo deseo, ahora en alianza con los españoles. Conviene citar la parte relevante de la Segunda Carta de Hernán Cortés :

También vinieron de ocho pueblos de la provincia de Coastoaca [...]. Y los naturales de los dichos ocho pueblos se ofrecieron asimismo por vasallos de vuestra alteza, y dijeron que otros cuatro que restaban en la dicha provincia vendrían muy presto ; y me dijeron que les perdonase porque antes no habían venido, que la causa había sido no osar por temor de los de Culua [aztecas] ; porque ellos nunca habían tomado armas contra mi, ni habían sido en muerte de ningún español, y que siempre, después que al servicio de vuestra alteza se habían ofrecido, habían sido buenos y leales vasallos suyos en sus voluntades, pero que no las habían osado manifestar por temor de los de Culua. (Cortés 1963, pp. 111, 112)

Veamos ahora los acontecimientos más transcedentes de los años posteriores. En 1522, Pedro de Alvarado fundó una población de españoles en Tututepec (en la Costa de Oaxaca) y dió Coixtlahuaca ("Coaslahuaca ») en encomienda a uno de los pobladores :

y los naturales de aquella provincia, y de la de Guaxaca, y Coaclan, y Coaslahuaca, y Tachquiaco, y otras allí comarcanos, se repartieron en los vecinos de aquella villa, y los servían y aprovechaban con toda voluntad ; y quedó en ella por justicia y capitán, en mi lugar, el dicho Pedro de Alvarado. (Cortés 1963, p. 205)

Lamentablemente, no sabemos quién fue este primer encomendero de Coixtlahuaca.

Un año después, los españoles despoblaron la villa y se trasladaron a Oaxaca. Al mismo tiempo, trás la muerte del cacique de Tututepec, la provincia de Tututepec « y las otras comarcanas » se rebelaron, por lo que Pedro de Alvarado tuvo que regresar a " pacificar » la región, usando el hijo del cacique como rehén.

Estando las cosas así, el cacique de Coixtlahuaca, desilusionado por la realidad de la colonia y pensando que la ausencia de los mexicas de su señorío, 
la rebelión de Tututepec y el caos en la fundación de la villa española, pudieran ser la oportunidad de « restaurar » el gran señorío de Atonaltzin, puede haber intentado imponer su dominio sobre la región, intento que le resultó fatal.

\section{REFLEXIONES FINALES}

Con el esquema histórico hipotético propuesto arriba, podríamos tratar ahora de interpretar la composición de los tres lienzos de Coixtlahuaca. En líneas anteriores ya se sugerió que el Lienzo de Coixtlahuaca y el Lienzo A corresponden al deseo de fijar a la vez el origen prehispánico y la afirmación colonial de los límites del señorío de Coixtlahuaca. Es un ejemplo de cómo un territorio, formado por pequeñas conquistas en las fronteras, es tranformado en un señorío colonial a través de la « petrificación » de sus linderos.

El mensaje del Lienzo de Coixtlahuaca II parece ser de un carácter más complejo. Como primer punto, es intrigante la inclusión del ahorcamiento en el lienzo. Todos los lienzos del valle de Coixtlahuaca muestran una fuerte tendencia a omitir acontecimientos políticamente adversos y perjudiciales para los linajes. La conquista por los aztecas está virtualmente ausente, con la posible excepción de una pequeña y oscura referencia en el Lienzo de Ihuitlán (Boone 2000, p. 141). ¿ Porqué entonces incluir al cacique ahorcado ? Sobre todo el joven Domingo no tendría ninguna razón para incluir la muerte de su padre y de hecho, como hemos visto, en sus escritos oculta la causa de su orfandad. También a su hijo, Juan de Zúñiga, en su intento de quedarse con el cacicazgo de Tejupan, le interesa en primer lugar la continuidad del linaje. La inclusión del ahorcamiento debe corresponder a un interés político muy particular. Ahora bien, sólo don Francisco y don Diego se beneficiaron de la muerte del cacique. Ellos, sin tener legítimo título al cacicazgo de Coixtlahuaca, quedaron a cargo como tutores del pequeño Domingo. Es probablemente la autoridad española, sentada en la silla, quien les señalo como los coadjutores. Es por esto que los dos hermanos están claramente presentes como testigos de la ejecución y es por esto que el joven Domingo, cuyo título legítimo no les convenía a los dos hermanos, está ausente. Creo que el lienzo fue hecho por orden de los dos regentes.

Es posible que la fecha de la elaboración sea bastante temprana. La presencia de don Francisco en el juicio, quien murió antes de 1540, la ausencia de don Domingo, y la necesidad de don Francisco y don Diego de referirse al momento de su instalación como administradores, lo sugieren así. Sin embargo, la presencia de dos iglesias en el lienzo es indicación de una fecha no demasiado temprana. En las ordenanzas de 1524, Cortés obliga a los encomenderos construir una iglesia « con su altar e imágenes » (Martínez 1990, p. 326), pero esta ordenanza parece haber tenido poco efecto, ya que no había suficientes sacerdotes. Hasta 1541, los de Coixtlahuaca tuvieron que ir a Yanhuitlán para escuchar la misa (Vences Vidal 2000, p. 181). 
Otro interesante elemento en el lienzo, que ayuda a vislumbrar las razones de su existencia, es la clara presencia de una serie de tierras en el norte del señorío. Desafortunadamente, la parte relevante está muy destruida, pero aún se distinguen cinco milpas alrededor de una iglesia, la cual se ubica en la orilla poniente del Río Juquila (Figura 8). El lugar está corriente abajo de los jeroglíficos que representan las maravillas naturales de las Huertas (Rincón Mautner 1999, p. 296 nota 70), y es probable que se trate del pueblo de San Jerónimo Juquila, el cual existió en esta posición geográfica y tenía su iglesia a la banda del poniente (AGI, Escribanía, 160B, f. 828 y 855 vta.). Si estoy en lo correcto, entonces las tierras deben corresponder a las milpas patrimoniales del cacicazgo de Coixtlahuaca, a las cuales ya se hizo referencia en una cita incluida en el primer párrafo de este artículo. El control de estas tierras productivas fue un asunto muy polémico durante todo el siglo Xvi y culminó en los años 70 con un desgastador pleito entre Coixtlahuaca y Zapotitlán sobre la posesión de esta parte, el cual fue ganado por Zapotitlán. Sin embargo, varios testigos en las diligencias insisten que Juquila fue conquistado por Coixtlahuaca en tiempos prehispánicos e invadido por Zapotitlán en la colonia temprana ${ }^{17}$. Veremos una de las declaraciones :

En tienpo de su infidelidad, antes q[ue]l Marq[ue]s y los españoles viniesen a esta Nueba España, vido y se acuerda este t[estig]o que, en el tienpo q[ue] los de (Cuis) tlahuaca y los demas de la Misteca tenian guerras con muchos pueblos, espeçialmente con los yndios nonuualcas, q[ue] son los q[ue] agora llaman de Teotitlan y Nextepec y Nanaguaticpac, y con otros comarcanos y con los yndios de la d[ic]ha estançia de Xoquila, en la d[ic]ha guera, entre otros, fueron vençidos los yndios de la d[ic]ha estançia de Xoquila por los de (Cues)tlahuacan, y luego fueron a poblar y poblaron la d[ic]ha estançia de Xoquila los d[ic]hos yndios de (Cuz)tlahuacan, y la tubieron, poseyeron y gozaron çiertos a[ñ]os hasta q[ue] vino el marq[ue]s y los españoles, quando se gano esta tierra, y luego dio enfermedad de birguelas a los naturales de la $\mathrm{d}[\mathrm{ic}]$ ha estançia de Xoquila y se murio la gente de la d[ic]ha estançia, como ansi mismo murio <murio> grande cantidad de naturales desta Nueva España de la d[ic]ha enfermedad, y luego como esto subçedio, por causa de ser la d[ic]ha estançia de Xoquila tan fertil de frutales de frutas desta tierra y mucha pesq[ue]ria del rrio q[ue] por alli pasa, su padre de don M[art]in [Pacheco] q[ue]s ya difunto, señor natural q[ue]ra del d[ic]ho pueblo de Çapotitlan, q[ue]ste t[estig]o no se acuerda como se llama, enbio a poblar y poblo la d[ic]ha estançia de Xoquila de la gente del d[ic]ho pueblo de Çapotitlan, y ansi despues aca, el d[ic]ho padre del d[ic]ho don M[art]in, en el tienpo $\mathrm{q}[\mathrm{ue}]$ bibio, y despues el d[ic]ho don M[art]in, governador q[ue]s agora del d[ic]ho pu[ebl]o de Çapotitlan, an tenido e tiene [...] por suya y su sujeta la d[ic]ha estançia de Xoquila. (AGI, Escribanía, 160B, f. 848 : Juan, gobernador de Tecolutla [hoy : San Juan los Cúes], de 96 años)

Posiblemente, el Lienzo de Coixtlahuaca y el Lienzo A representan esta conquista de Juquila, dibujado como "Río de Orejas » y " Casa de Orejas y 


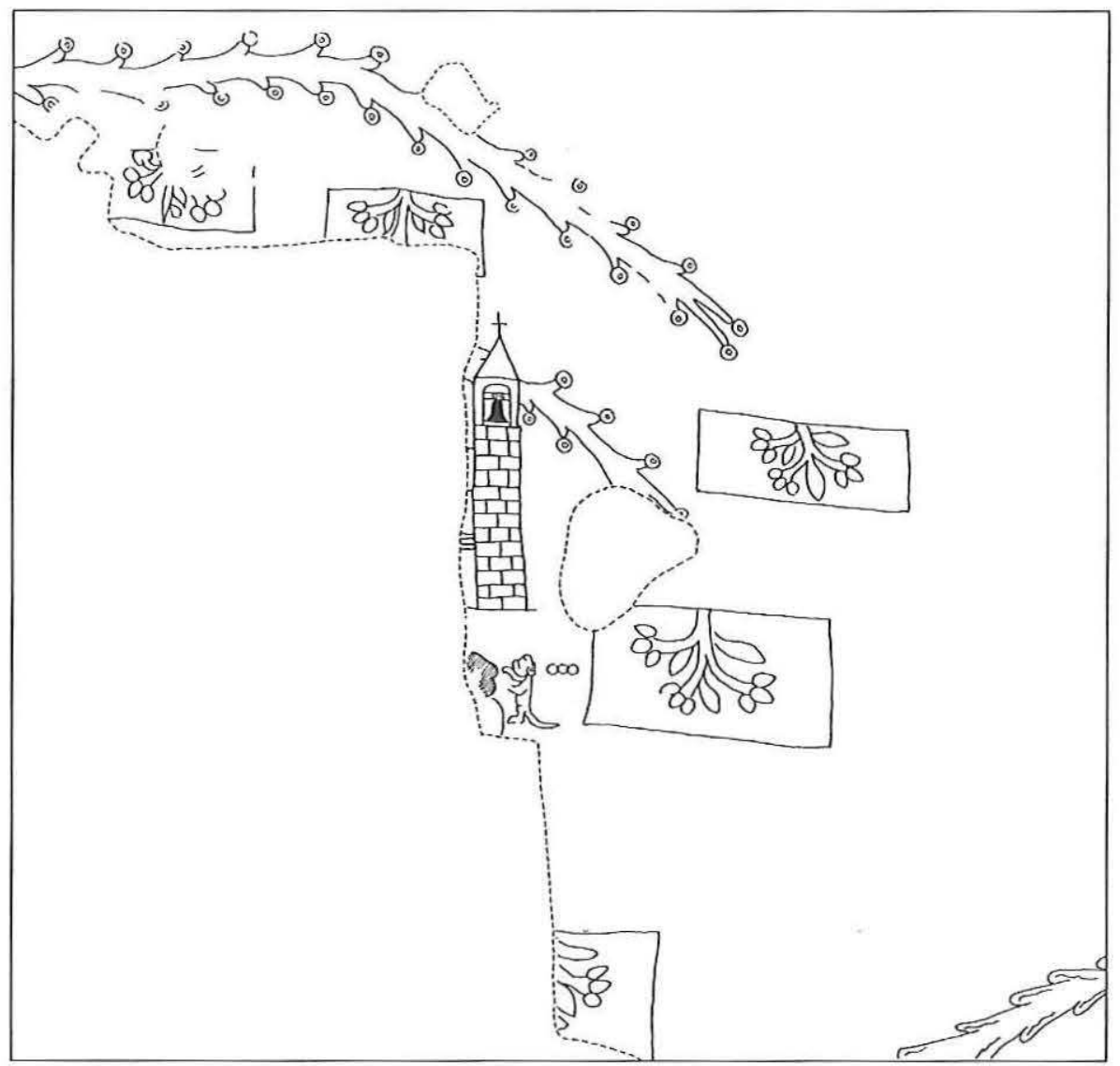

FIG. 8 - La iglesia de Juquila con las cinco milpas de los señores (Lienzo de Coixtlahuaca II). Aún se distingue el nombre Tres-Lagartija de la esposa del señor del lugar. El norte está hacia abajo, por donde corre el Río Hondo o Río Calapa. [Dibujo Bas van Doesburg]

Cascada » (Figura 9) (Rincón Mautner 1999, p. 338) ${ }^{18}$. Dada esta situación, es posible que la inclusión de las tierras de Juquila reflejó el deseo de asegurar esta posesión.

Más aún, es posible que la manufactura de todo el documento correspondió a un intento de los dos regentes de legitimar su posición impuesta por afuera y posiblemente cuestionada desde adentro por los otros nobles. En 1524, el español incluido en el lienzo, ya que era la autoridad que legitimaba su regencia, probablemente no tenía idea de lo que era el señorío de Coixtlahuaca, excepto de que se trataba de una "gran provincia ». Para don Francisco y don Diego, su 


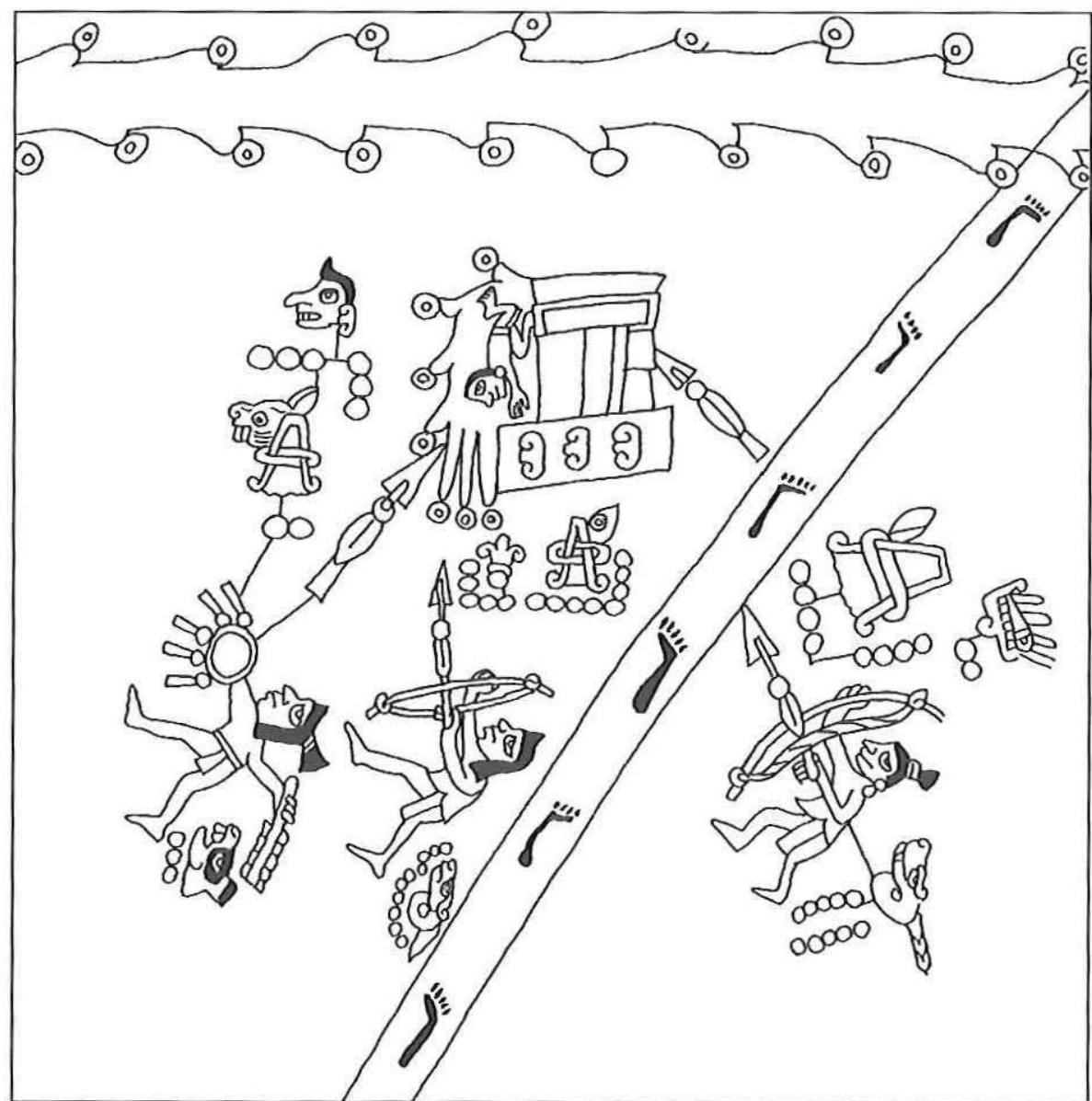

FIG. 9 - La conquista de un lugar que podría ser Juquila (Lienzo de Coixtlahuaca). El norte está hacia la izquierda, el río es el actual Río Hondo o Río Calapa. El lugar se encuentra atacado dos veces por el señor Diez-Serpiente, el padre de Atonaltzin, en el año de 1436. El señor Tres-Perro puede ser el tatarabuelo o el bis-bisnieto de Diez-Serpiente. [Dibujo Bas van Doesburg]

nombramiento significó una posibilidad de apoderarse de la historia del legítimo linaje, de su poder, de su prestigio y de sus tierras. El lienzo mostraba en detalle todo lo que fue, según su interpretación, aquello a que tenían derecho ${ }^{19}$. Lo preocupante era que su posición dependía de la merced del colonizador español y no de las reglas indígenas de sucesión ${ }^{20}$.

En este contexto, es interesante señalar que fue también durante su administración que los frailes domínicos se establecieron en Coixtlahuaca. En 1541, 
Francisco Marín comienza a llegar a Coixtlahuaca. La construcción de la primera iglesia debe haber ocurrido poco después. En 1544 se crea la doctrina y en 1546 Marín se establece como vicario. Es en esta fecha que se comienza a construir la hermosa capilla abierta que aún existe (Vences Vidal 2000, p. 188). Es posible que los dos administradores indígenas querían, para mejor legitimar su gobierno, mostrar su apoyo en la evangelización del señorío. La presencia de la iglesia de Coixtlahuaca y la conspicua inclusión de la iglesia de Juquila (quizás construida bajo sus auspicios) en el Lienzo de Coixtlahuaca II puede corresponder a este objetivo.

Para finalizar, es de notarse que, a pesar de la presencia española en algunos de los documentos, no existe indicación alguna en los documentos alfabéticos registrados hasta ahora que los lienzos del valle de Coixtlahuaca alguna vez fueron presentados ante una autoridad española como pruebas en alguno de los múltiples juicios por linderos y tierras. Esto puede ser debido a la pérdida de documentación que sufrió el archivo de Coixtlahuaca ${ }^{21}$. Así, es posible que el Lienzo de Coixtlahuaca y el Lienzo A estuvieron originalmente acompañados por un expediente (ahora perdido) relacionado con el establecimiento de los linderos coloniales de Coixtlahuaca. Sin embargo, en otros casos esto es poco probable. El Lienzo de Ihuitlán, por ejemplo, parece más bien ser un documento de exclusivo " uso interno » : la inclusión de referencias claras a númenes y bultos sagrados de origen prehispánico ya indica que el contenido del documento no estaba destinado a ojos españoles. Además, parece posible que el documento fue elaborado para un eventual matrimonio entre una princesa de Ihuitlán y un hijo de la pareja gobernante de Coixtlahuaca, lo que sería una cuestión interna con poca relevancia para la administración española ${ }^{22}$. De hecho, el documento carece de representaciones de españoles (con la excepción de la referencia indirecta a la nueva religión bajo la forma de la capilla de Santiago) ${ }^{23}$.

Quizás no es un elemento coincidencial el hecho que los tres documentos de Coixtlahuaca se refieren al contacto con los españoles, mientras los lienzos de los demás señoríos del valle guardan silencio al respecto. Coixtlahuaca fue la cabecera del señorío, el lugar donde se estableció uno de los complejos conventuales más grandes del territorio oaxaqueño y donde a veces arribaron los corregidores y alcaldes mayores de Teposcolula y Tejupan en representación de la administración española. Sin embargo, y a pesar de la presencia española en los documentos de Coixtlahuaca, es cuestionable si los documentos jamás fueron contemplados por ojos españoles durante el siglo XVI. Los acervos documentales alfabéticos conservados hasta nuestros días indican que los señores indígenas preferían, ya a partir de los años 40 , la escritura alfabética para su correspondencia con la administración española ${ }^{24}$.

Esta distinción, y la - a menudo hipotética - identificación de la particular razón u ocasión para la elaboración de cada documento, la cual a mi sentir debe buscarse generalmente en el ámbito local e indígena, nos recuerdan que esta 
extraordinaria literatura indígena es, a pesar de similitudes en soporte, técnica y escritura, diversa de carácter y, sobre todo, coyunctural. Desde este punto de vista, cada documento se vuelve testimonio de la complejidad de la fascinante sociedad indígena del siglo xvI. *

\section{Cuadro genealógico}

\begin{tabular}{|l|l|}
\hline DTlitteuhctli $(\ldots-1524)-*$ Ocelosuchitl & $\begin{array}{l}\text { Francisco }(\ldots-1540) \text { y Diego de Castilla } \\
\text { tutores de Domingo }\end{array}$ \\
& $\begin{array}{l}\text { Francisco Maldonado y Tomás Vanegas } \\
\text { tíos de Pedro y Juan }\end{array}$ \\
Pedro de Mendoza (ca. 1546 - ...) & $\begin{array}{l}\text { Esteban de San Juan } \\
\text { tutor de Pedro y Juan }\end{array}$ \\
\hline
\end{tabular}

* Manuscrit reçu en juillet 2002, accepté pour publication en juin 2003.

\section{NOTAS}

\section{Abreviaturas}

AAT Archivo Antiguo de San Miguel Tequixtepec.

AGI Archivo General de Indias, Sevilla.

AGN Archivo General de la Nación, México.

AJT Archivo del Poder Judicial de Oaxaca, Ramo Teposcolula.

1. Esta interpretación fue propuesta por Mary Elizabeth Smith en su influencial libro de 1973 (p. 169) en relación a un reducido grupo de documentos mixtecos. Posteriormente, ella sugerió que el formato de la " columna genealógica » vertical, común en muchos lienzos, podría estar inspirado en los requerimientos de las cortes españoles (Smith and Parmenter 1991, pp. 20, 32), extendiéndose así el carácter de " documento jurídico » a casi todos los lienzos. La implicación indeseada de esta idea seria que casi todos los lienzos fueron elaborados para ser presentados ante cortes españolas. Como trataré de demostrar en adelante, tal interpretación es cuestionable.

2. Existen varias publicaciones sobre los documentos pictográficos del valle de Coixtlahuaca, por ejemplo Caso 1958, 1961 y 1979 (II) ; Doesburg y Buren 1997 ; Doesburg 2000 y 2001 a ; Johnson 1994 ; König 1984 ; Parmenter 1982 ; Rincón Mautner 1999. Se conocen doce documentos : los Lienzos de Tequixtepec I y II, el Lienzo de Tulancingo y el Lienzo de Nativitas (todos en sus respectivos pueblos), el Lienzo de Tlapiltepec (Royal Ontario Museum, Toronto), el Lienzo de Ihuitlán (Brooklyn Museum, Nueva York), el Lienzo de Coixtlahuaca (Museo nacional de antropología e historia, México), el Lienzo Seler II o de Coixtlahuaca II (Ethnografisches Museum, Berlin), el Lienzo A (una copia hecha alrededor de 1900 de un original perdido ; Latin-American Library de Tulane, New Orleans), el Códice Baranda (Museo nacional de antropología e historia, México), el Rollo Selden (Bodleian Library, Oxford) y el Fragmento Gómez de Orozco (colección privada). Este último documento está incompleto. Un documento adicional, el Lienzo de Aztatla, mencionado por Rincón Mautner (1999), está tan deteriorado que no ha sido posible interpretarlo. 
3. En el centro de México, donde se produjo una importante tradición historiográfica alfabética después de la Conquista, y donde el estudio de estos documentos pictográficos y alfabéticos de los " aztecas» fue parte de la construcción del nacionalismo criollo, el estudio de los documentos pictográficos en relación con la documentación alfabética se estableció en fechas mucho más tempranas que en Oaxaca. No obstante, también en aquella región, el estudio de los textos alfabéticos en lengua indígena (en este caso nahuatl), tuvo un retraso considerable y no fue hasta los años $70 \mathrm{del}$ siglo xx que se comenzó a disponer de traducciones confiables de los más importantes textos. Tanto en el centro de México, como en Oaxaca, el interés en los documentos más « mundanos » (testamentos, contratos, juicios, cartas, etc.) en español y en lenguas indigenas como fuentes para la reconstrucción del contexto histórico de la producción de los documentos pictográficos es reciente. Véase Ruíz Medrano y Valle (1998, p. 231 nota 13) con énfasis en casos jurídicos en los que textos alfabéticos y pictografia forman parte del mismo expediente. Para Oaxaca, puede mencionarse además los trabajos de Smith (1973), Smith and Parmenter (1991), Jansen (1994), Herrera y Ruiz (1997), Oudijk (2000), Doesburg (2001b), y Hermann Lejarazú (2003).

4. La propuesta es de carácter hipotético. Futuros estudios seguramente modificarán partes de esta propuesta. Agradezco los comentarios de Nicholas Johnson y de los dictaminadores anónimos del Journal de la Société des Américanistes a una primera versión de este artículo.

5. Una carta en mixteco conservada en el Archivo municipal de Santa María Nativitas, indica que en la segunda mitad del siglo XVII un Juan de Zúñiga II - posiblemente un descendiente de Juan de Zúñiga - recibió, de la familia Lara, el cacicazgo de Santa Domingo Chiyo Cani, hoy llamado Chocani (Documentos sin inventario, archivo municipal Santa María Nativitas). Este Juan de Zúñiga II también aparece como cacique de Tianguistengo o Chiyocani en AGN [Tierras, vol. 2732, exp. 18 (1670) y vol. 2985, exp. 183 (1670)].

6. Curiosamente, Juan de Zúñiga se presenta como el hijo mayor en los documentos de Tejupan. Esta aparente contradicción se resolvería si Juan y Pedro fueran hijos de diferentes madres. Quizás, doña Ana, la madre de Juan, fue cacica de (una parte de) Tejupan. Desafortunadamente, no ha sido posible identificar a doña Ana en los documentos sobre Tejupan.

7. En otro documento (AGN, Civil, vol. 726, f. 76, 1545), don Domingo dice : « quinze años e mas t[iem]po a quel pu[ebl]o de Cuestlavaca no tiene señor nat[ur]al e el q[ue]s agora ques don Domingo es menor de beynte e çinco años » (posteriormente se tachó, por razones desconocidas, la palabra " çinco »). Curiosamente, los testigos en este documento sostienen que fue sólo desde hace dos años (desde 1543) que Coixtlahuaca estuvo sin señor. Esto podría ser una indicación para la muerte de un gobernante en 1543, pero no he podido indentificarlo.

8. El texto en nahuatl y su traducción al inglés fue publicado por Kevin Terraciano (1994, p. 624). Este texto es la primera referencia a las tierras de estos caciques en el norte del valle de Coixtlahuaca, en Aztatla, Tonalá y Juquila.

9. Como veremos después, el mencionado don Francisco no es el hermano de don Diego, ya que aquel ya se había muerto antes de 1540. Es curioso encontrar aquí de nuevo a un don Domingo de Mendoza, ya que éste había muerto en 1552. Se trata aquí probablemente de otro cacique del mismo nombre.

10. En marzo de 1552, unos meses antes de la presentación de Pedro y Juan como herederos de Domingo, Esteban de San Juan, alcalde (y tutor de los jóvenes Pedro y Juan), y los tíos Tomás y Francisco visitaron la audiencia para arreglar un asunto del tributo con su encomendero Alonso de Bazán (Libro de las Tasaciones 1952, p. 151).

11. No obstante, existen varios casos tempranos en que los españoles ahorcaron a los nobles acusados de « idolatría ». El caso de los nobles tlaxcaltecos ahorcados por orden de los frailes por « idolatría » en 1527 es un caso conocido (Gibson 1991, p. 46) y en 1531 fray Alonso de Juárez ahorcó a un señor de Cuauhtinchan por cantar himnos sagrados («tlacatecolocuicatl », según la fuente) (Celestino Solís y Reyes Garcia 1992, pp. 25, 26 ; Kirchhoff, Odena Güemes y Reyes García 1989, p. 231).

12. Caso $(1979$, p. 134) leyó Dos-Agua, pero en el original se ve solamente una bolita. Muy a la derecha de la escena, al lado derecho de la iglesia, se encuentran otros dos señores, cuyos nombres, 
aparentemente « nombres personales », están hoy en día ilegibles. Además, se ven los restos de cuatro figuras muy dañadas. Todos estos parecen haber sido también testigos de la ejecución.

13. De hecho, aún más a la derecha se registraron otros dos encuentros o visitas, aparentemente de la época prehispánica. El primer encuentro lleva la fecha año Diez-Caña, día Seis-Lagarto (1503), y el segundo ocurrió en la fecha año Doce-Conejo, día Trece-Lagarto (1518), el año del arribo de los españoles en México, este último visible en la figura 5.

14. La fecha de 1544 podría referirse a una visita anterior del mismo juez Gaspar de San Martín, corregidor de Nochixtlán, el cual, en este año, realizó un amojonamiento de Tequixtepec ý Coixtlahuaca por orden de la real audiencia (Doesburg 2002, p. 35).

15. El Lienzo de Tlapiltepec, el Lienzo de Coixtlahuaca y el Lienzo A (todos de Coixtlahuaca) representan únicamente las primeras dos parejas de la serie del Lienzo de Coixtlahuaca II. Esto sugiere que la diferencia entre el Lienzo de Coixtlahuaca II y el Lienzo de Ihuitlán refleja una diferencia de tradición entre los pueblos de Coixtlahuaca e Ihuitlán acerca de la sucesión en Coixtlahuaca.

16. En tres documentos (el Lienzo de Tlapiltepec, el Lienzo de Coixtlahuaca y el Lienzo A), el señor Once-Zopilote « cierra » el linaje de Coixtlahuaca. Como sugerió Nicholas Johnson (com. pers.), Once-Zopilote puede haber sido el gobernante en el momento de la Conquista. Incluso, es posible que sea idéntico al rey Cozcaquauhtli en la historia de Torquemada (Doesburg and Buren 1997, p. 145) quien asumió el gobierno de Coixtlahuaca en la primera década del siglo xvi. En esta solución, el linaje de Coixtlahuaca no terminaría inexplicablemente dos generaciones antes de la Conquista en los dichos tres documentos. Dos lienzos coinciden en que el Señor Diez-Conejo era el último gobernador de Coixtlahuaca. Es sugestivo que el ahorcamiento está dibujado directamente arriba de él. Por lo tanto, puede ser este mismo quien fue ahorcado. En tal caso, las cuatro generaciones después de Atonaltzin habrían gobernado solamente un promedio de 16 años.

17. El control de Juquila puede haber implicado también un aspecto ideológico. Como sugiere el documento AGI (Escibanía, 160B), Juquila puede haber sido una fundación nonoualca. Los nonoualca, un grupo de nahuatl-hablantes proveniente del norte, fundaron varios pueblos en la región de Tehuacán (Teotitlán, Coxcatlán, Tehuacán y Zongolica) en el siglo xI. La Historia toltecachichimeca (Kirchhoff, Odena Güemes y Reyes García 1989, p. 141) menciona Juquila entre los linderos de los nonoualca. Desde Juquila, y a través de sus alianzas matrimoniales, los nonoualca distribuyeron los principales símbolos primordiales de los nahuas (Chicomoztoc y Coatepec) por el valle de Coixtlahuaca. El hecho que también el linaje de Coixtlahuaca retoma estos símbolos en su historia de origen indica un estrecho lazo ideológico entre los señores de Coixtlahuaca y los de Juquila.

18. Un argumento adicional a favor de esta identificación es la existencia de cuatro glifos con glosas en la orilla del Lienzo de Coixtlahuaca, a la altura de "Casa de Orejas y Cascada " : de poniente a oriente catehoo (glifo : " piedra en medio de dos cerros »), casogiyu (glifo : « cerro con tubo de agua »), ro :haa (glifo : « cerro de águila ») y qui ... Ja (glifo : " cerro de planta »). Tres de los glifos y todas las glosas parecen ser posteriores a la pintura original del lienzo. Sin embargo, la ortografia de las glosas y el estilo de los glifos sugieren a la vez una fecha temprana para su elaboración. Sólo el glifo arriba de la glosa ro: haa parece ser original. Estos nombres corresponden a cuatro linderos entre Juquila por una parte y Nanahuatipan y Nextepec (hoy San Gabriel Casas Blancas) por otra, según el documento AGI (Escribanía, 160B, f. 835vta). Catehoo coincide con Cateho, el nombre popoloca de Telnepantla ( « piedra en medio ») ; a pesar de las diferencias en ortografia, casogiyu coincide con Axoxio, el nombre popoloca del lindero Alpiaztla (« lugar de conductos de agua ») : en la ortografia del chocho y del mixteca del siglo xvi, la -s- sonó como la -sh- del inglés. El mismo sonido fue escrito a veces como -xEn los primeros documentos en chocho [AAT-39, 1577], la -g-representó el sonido -sh- del inglés como retroflejo, un sonido representado después por la -x-; ro :haa coincide con Catohohaa, el nombre popoloca del lindero Cuauhtepec («cerro de águila »). Finalmente, qui[..ja podría coincidir con Guigua, el nombre popoloca de Zacualyxtlahuaca. Son justamente estos cuatro puntos que son centrales en el pleito entre Coixtlahuaca y Zapotitlán sobre la posesión de Juquila. Los cuatro lugares aparecen, con nombres en nahuatl, también en el Lienzo de Coixtlahuaca II cerca de la iglesia identificada como Juquila. 
19. Es, sin embargo, relevador que en sus lienzos ellos no osaron presentarse como sucesores del linaje gobernante. Después del señor Diez-Conejo no se registró ningun gobernante de linaje. Esto refuerza la idea según la cual don Diego y don Francisco se vieron como los administradores de la herencia de la casa real de Coixtlahuaca.

20. La misma tendencia de recurrir a la autoridad española para legitimar en este caso el territorio del señorío mismo la vemos en la visita de los jueces españoles para establecer los linderos coloniales de Coixtlahuaca.

21. En 1980 se perdió el archivo municipal a causa de un temblor. Sabemos, por referencias dispersas, que en el siglo xviII Coixtlahuaca aún conservaba un extenso archivo con documentos del siglo xvi. Entonces, los eventuales documentos relacionados con los lienzos de Coixtlahuaca pueden haberse perdido. Sin embargo, en Tequixtepec, donde se conserva hasta ahora un archivo municipal en excelentes condiciones, no existe ninguna referencia a los dos lienzos de la población, anterior a la segunda mitad del siglo XVIII, cuando los lienzos comienzan a aparecer en los inventarios de la presidencia.

22. El linaje principal de Ihuitlán termina con la pareja Señor Uno-Zopilote y Señora OchoVenado (véase figura 6). A la izquierda, ligeramente arriba de sus padres, está su hija Siete-Flor. Directamente a la izquierda del linaje de Ihuitlán corre el linaje de Coixtlahuaca, el cual termina con el Señor Diez-Conejo y la Señora Cinco-Venado. Arriba de ellos existe un espacio vacío frente a la señorita Siete-Flor, donde podría colocarse el hijo de los primeros, esposo de la última. Esta interpretación explicaría la inclusión del linaje de Coixtlahuaca en este documento de Ihuitlán. Además, como se notó en la nota 14, existen indicaciones para un conflicto entre Coixtlahuaca e Ihuitlán por la descendencia en el linaje de Coixtlahuaca. Estos conflictos se solucionaban a menudo a través de casamientos políticos. Para una explicación similar en relación al Códice Selden de la Mixteca, véase Jansen y Pérez Jiménez (2000, pp. 23-24). Una semejante interpretación « interna » es discutida por Swanton (2001) en relación a la famosa Historia tolteca-chichimeca.

23. Este aspecto "autóctono" confiere a este documento un carácter distinto a los llamados " códices jurídicos » o los « títulos primordiales », los cuales surgieron en el punto de contacto entre las autoridades coloniales y los pueblos indígenas (Ruíz Medrano y Valle 1998 ; Florescano 2001). El concepto del « producto híbrido » (Florescano ibid., p. 39) quizás se aplicaría en el centro de México, donde la presencia española $y$, por lo tanto, la interacción cultural, era mucho más fuerte, pero difícilmente encuentra sentido en Oaxaca durante el siglo xvi. Florescano, sin contemplar las peculiaridades del Lienzo de Ihuitlán, reune este documento, con muchos otros de diferentes épocas, regiones y características, bajo el solo denominador heterógeno de « títulos primordiales ». Curiosamente, este autor distingue entre una primera etapa (la de la elaboración de una crónica de realeza) y el reuso posterior como documento jurídico, solamente para después negar la primera y concluir que estos documentos no pueden llamarse " obras indígenas ".

24. Curiosamente, la única referencia clara al uso de un documento pictográfico en un juicio durante el siglo Xvi en el valle de Coixtlahuaca concierne la elaboración de un mapa jeroglifico por orden de un juez español durante el pleito entre Coixtlahuaca y Zapotitlán, en 1571 (AGI, Escribanía 160B, f. 828 et passim). Este mapa se ha perdido.

\section{REFERENCIAS}

\section{Anales de Cuauhtitlán}

1975 en Códice Chimalpopoca, Universidad Nacional Autónoma de México, México.

\section{Boone Elizabeth Hill}

2000 Stories in red and black. Pictorial histories of the Aztecs and Mixtecs, University of Texas Press, Austin. 
BUREN Olivier van

1996 El Lienzo de Tulancingo y la historia prehispánica del valle de Coixtlahuaca, Tesis de maestría de la Universidad de Leiden, Leiden.

CAso Alfonso

1949 "Elmapa de Teozacoalco », Cuadernos americanos, VIII(5), pp. 145-181.

1958 "Comentario al Códice Baranda », en Miscelanea Paul Rivet, Octogenario dicata, I, pp. 373-394, Universidad Nacional Autónoma de México, México.

1961 "Los lienzos mixtecos de Ihuitlán y Antonio de León », en Homenaje a Pablo Martínez del Río (... ), pp. 237-274, Instituto Nacional de Antropología e Historia, México.

1979 Reyes y reinos de la Mixteca, I y II, Fondo de cultura económica, México.

Celestino Solís Eustacio y Luis Reyes García (traducción y notas)

1992 Anales de Tecamachalco, 1398-1590, Fondo de cultura económica, Centro de investigaciones y estudios superiores de antropología social, Estado de Puebla, México.

CoRTÉs Hernán

1963 Cartas y documentos, Editorial Porrúa, México.

DoEsBurg Sebastian van

2000 " Origin of the Lienzo de Tulancingo, new facts about a pictographic document from the Coixtlahuaca region ", Ancient Mesoamerica, 11, pp. 169-183.

2001a «De linderos y lugares, territorio y asentamiento en el Lienzo de Santa María Nativitas », Relaciones, XXII, 86, pp. 15-82, Colegio de Michoacán, Zamora.

2001b Códices cuicatecos Porfirio Diaz y Fernández Leal, Editorial Miguel Angel Porrúa, México.

2002 Documentos antiguos de San Miguel Tequixtepec, Oaxaca. Los primeros cien años de la Colonia (1533-1617), Research School of Asian, African and Amerindian Studies (CNWS), Leiden University, Leiden.

DoEsBurg Sebastian van and Olivier van BUREN

1997 "The prehispanic history of the valley of Coixtlahuaca, Oaxaca ", Cuadernos de historia latinoamericana, 5 (Maarten Jansen y Luis Reyes García, eds, Códices, caciques y comunidades), pp. 103-160.

Doesburg Sebastian van and Michael Swanton

en prensa «Philology as an interdisciplinary study : the Xru Ngiwa «barrios» of Tamazulapan ", University of California, Los Angeles.

DurÁn Diego

1984 Historia de las indias de Nueva España e islas de la Tierra Firme, I, Editorial Porrúa, México.

Florescano Enrique

2001 «Titres primordiaux et mémoire canonique en Méso-Amérique », Études Rurales, 157-158, pp. 15-43. 
Ginson Charles

1991 Tlaxcala en el siglo Xvi, Fondo de cultura económica, México [1952].

GreEnLEAF Richard E.

1988 Zumárraga y la inquisición mexicana, 1536-1543, Fondo de cultura económica, México.

Herrera Carmen y Ethelia Ruiz

1997 El entintado mundo de la fijeza imaginaria : el Códice de Tepeucila, Instituto Nacional de Antropología e Historia, México.

Hermann Lejazarú Manuel

2003 Códice Muro. Un documento mixteco colonial (Códices Oaxaqueños II), Secretaría de asuntos indígenas del Gobierno del Estado de Oaxaca y Biblioteca nacional de antropología e historia, Oaxaca.

JANSEN Maarten

1994

La gran familia de los reyes mixtecos. Libro explicativo de los códices llamados Egerton y Becker II (Códices Mexicanos IX), Akademische Druck- und Verlagsanstalt, Austria y Fondo de cultura económica, México.

1998 " Purpose and provenience of the Mixtec Codices », Indiana Journal of Hispanic Literatures, 13 (Gordon Brotherston, ed., Mexican codices and archeology), pp. 31-46.

JANSEN Maarten y Aurora PÉrez JimÉNEZ

2000 La dinastía de Añute. Historia, literatura e ideología de un reino mixteco, Research School of Asian, African and Amerindian Studies (CNWS), Leiden University, Leiden.

JOHNSON Nicholas

1994 «Las líneas rojas desvanecidas en el Lienzo de Tlapiltepec, una red de pruebas ", en Constanza Vega Sosa, ed., Códices y documentos sobre México, Instituto Nacional de Antropología e Historia, México, pp. 117144.

KirchHoff Paul, Lina Odena GüEmes y Luis ReYes García (edición, traducción y notas) 1989 Historia tolteca-chichimeca, Fondo de cultura económica, Centro de investigaciones y estudios superiores de antropología social, Estado de Puebla, México [1976].

KöNIG Viola

1979 Inhaltliche Analyse und Interpretation von Codex Egerton (Beiträge zur mittelamerikanischen Völkerkunde, XV), Hamburgischen Museum für Völkerkunde, Hamburg.

1984 "Der Lienzo Seler II und seine Stellung innerhalb der CoixtlahuacaGruppe ", en Baesler Archiv, Neue Folge, XXXII, Verlag von Dietrich Reimer, Berlin.

(El) Libro de las Tasaciones de Pueblos de la Nueva España, Siglo xvı

1952 Archivo general de la Nación, México. 
MaRTínez José Luis

1990 Documentos cortesianos, I (1518-1528), Universidad Nacional Autónoma de México, Fondo de cultura económica, México.

OudIJK Michel

2000 Historiography of the Benizaa. The postclassic and early colonial periods (1000-1600 A.D.), Research School of Asian, African and Amerindian Studies (CNWS), Leiden University, Leiden.

PARMenter Ross

1970 " The identification of Lienzo A. A tracing in the latin american library of Tulane university ", Philological and documentary studies, II (5), Tulane University, Middle American Research Institute, New Orleans.

1982 Four Lienzos of the Coixtlahuaca valley, Dumbarton Oaks, Trustees for Harvard University, Washington, coll. "Studies in Precolombian Art \& Archaeology » 26.

RinCón MAUTner Carlos Arturo

1999 Man and the environment in the Coixtlahuaca Basin of Northwestern Oaxaca, Mexico : two thousand years of historical ecology, $\mathrm{PhD}$ dissertation at the University of Texas, Austin.

Ruíz Medrano Ethelia y Perla Valle

1998 «Los colores de la justicia. Códices jurídicos del siglo xvi en la Bibliothèque nationale de France ", Journal de la Société des Américanistes, 84 (2), pp. $227-241$.

SмIтн Mary Elizabeth

1973 Picture writing from ancient Southern Mexico. Mixtec place signs and maps, University of Oklahoma Press, Oklahoma.

SMith Mary Elizabeth and Ross PARmenter

1991 The Codex Tulane, Akademische Druck- und Verlagsanstalt, Austria \& Middle American Research Institute, Tulane University, New Orleans.

Swanton Michael W.

2001 "El texto popoloca de la historia tolteca-chichimeca », en Relaciones, XXII (86), Iconografia y Gobierno Indigena, Zamora.

Terraciano Kevin

1994 Nudzahui history. Mixtec writing and culture in colonial Oaxaca, PhD dissertation at the University of California, Los Angeles.

Torquemada Juan de

1986 Monarquía indiana, I, Editorial Porrúa, México.

VENCES Vidal Magdalena

$2000 \quad$ Evangelización y arquitectura dominicana en Coixtlahuaca Editorial San Esteban, Salamanca, coll. « Monumenta Histórica Iberoamericana de la Orden de Predicadores » XVIII.

Zavala Silvio

1982 Libros de asientos de la gobernación de la Nueva España. Periodo del virrey don Luis de Velasco, 1550-1552, Archivo general de la Nación, México, coll. « Documentos para la Historia » 3. 